\title{
Targeted metagenomics demonstrates the ecological role of IS1071 in bacterial community adaptation to pesticide degradation
}

\author{
Vincent Dunon, ${ }^{1}$ Karolien Bers, ${ }^{1}$ Rob Lavigne, ${ }^{2}$ \\ Eva M. Top $^{3}$ and Dirk Springael ${ }^{1 *}$ \\ ${ }^{1}$ Division of Soil and Water Management, KU Leuven, \\ Kasteelpark Arenberg 20 Box 2459, 3001 Heverlee, \\ Belgium. \\ ${ }^{2}$ Laboratory of Gene Technology, KU Leuven, \\ Kasteelpark Arenberg 21 Box 2462, 3001 Heverlee, \\ Belgium. \\ ${ }^{3}$ Department of Biological Sciences, Institute for \\ Bioinformatics and Evolutionary Studies, University of \\ Idaho, Moscow, Idaho, USA.
}

\section{Summary}

IS1071, an insertion element that primarily flanks organic xenobiotic degradation genes in cultured isolates, is suggested to play a key role in the formation and distribution of bacterial catabolic pathway gene clusters. However, in environmental settings, the identity of the IS1071 genetic cargo and its correspondence to the local selective conditions remain unknown. To respond, we developed a long-range PCR approach amplifying accessory genes between two IS1071 copies from community DNA followed by amplicon sequencing. We applied this method to pesticide-exposed environments, i.e. linuron-treated agricultural soil and on-farm biopurification systems (BPS) treating complex agricultural wastewater, as to non-treated controls. Amplicons were mainly recovered from the pesticide-exposed environments and the BPS matrix showed a higher size diversity compared to the agricultural soil. Retrieved gene functions mirrored the main selection pressure as (i) a large fraction of the BPS amplicons contained a high variety of genes/gene clusters related to the degradation of organics including herbicides present in the wastewater and (ii) in the agricultural soil, recovered genes were associated with linuron degradation. Our

Received 7 February, 2017; revised 9 August, 2018; accepted 6 September, 2018. *For correspondence. E-mail dirk.springael@ kuleuven.be; Tel. ++32 163216 04; Fax ++32 16321997. metagenomic analysis extends observations from cultured isolates and provides evidence that IS1071 is a carrier of catabolic genes in xenobiotica stressed environments and contributes to community level adaptation towards pesticide biodegradation.

\section{Introduction}

Horizontal gene transfer (HGT) is a prime mechanism by which bacteria acquire abilities to catabolize recalcitrant organic compounds (Top and Springael, 2003). Mobile genetic elements (MGEs), such as plasmids and transposons, not only control the dispersion of catabolic genes but are also the gateway to an open source evolution of metabolic pathways by (re)combination of suitable catabolic gene modules (Iwasaki and Takagi, 2009).

An MGE that shows a remarkably frequent association with genes encoding organic xenobiotic degradation in bacteria is the insertion sequence IS1071. This element was first described bordering the 3-chlorobenzoate catabolic genes on the Pseudomonas sp. (renamed as Comamonas testosteroni) BR60 plasmid pBRC60 (Fulthorpe and Wyndham, 1992). Since then, it was reported to border various other organic xenobiotic catabolic - often plasmid-encoded - gene clusters in xenobiotic degrading bacteria (Bers et al., 2011; Martinez et al., 2001; Vedler et al., 2004; Sen et al., 2010; Ledger et al., 2006). With its $3.2 \mathrm{~kb}$ in length and $110 \mathrm{bp}$ long inverted repeats, IS1071 is a unique IS element and, unlike other IS elements, is categorized as a class II transposon based on the transposase $(\operatorname{tnp} A)$ gene sequence (Sota et al., 2008). Often IS1071 flanks the catabolic genes at both sites forming a putative composite transposon that in the case of pBRC60 was shown to effectively transpose as an entity between replicons (Fulthorpe and Wyndham, 1992). Plasmids that often carry such apparent IS1071 catabolic composite transposons are the highly promiscuous plasmids of the IncP-1 group, suggesting that IS1071 mediates the recruitment of the catabolic genes by IncP-1 plasmids upon which the composite transposon can be further distributed (Dennis, 2005; Nojiri et al., 2004; Top and Springael, 2003). 
All these conclusions are based on information from cultured strains often isolated from enrichment cultures with the application of highly selective conditions. Less is known about the occurrence of IS1071 and especially its cargo genes in environmental settings and their complex communities. Unusually high IS1071 abundances were recorded in organic xenobiotic exposed natural and engineered ecosystems such as agricultural soils treated with pesticides and on-farm biopurification systems (BPSs) that treat pesticide contaminated wastewater at farms, indicating the implication of IS1071 in genetic adaptation of microbiota towards organic xenobiotic biodegradation in environmental settings and hence the ecological relevance of IS1071 (Dunon et al., 2013; Dealtry et al., 2014a, 2014b). However, it is unclear whether IS1071 elements in natural environments are associated with functional genes and whether those accessory genes can be linked with the local selective forces such as the presence of organic xenobiotics. Such knowledge is needed to fully grasp and acknowledge the ecological role of IS elements like IS1071 as mediators in community adaptation in the environment.

Metagenomics based on shotgun sequencing of community DNA by next-generation sequencing (NGS) is a powerful tool to explore the functional diversity within microbial communities. However, in case of environments with complex communities, such as soils, retrieving gene functions of interest and determining their genetic context from metagenomic sequence data is a challenge especially when the corresponding bacterial populations compose only a small fraction of the total community. The latter is often the case for xenobiotica-degrading bacteria as the xenobioticum only represents a minor fraction of the available carbon for growth. For instance, several recent studies show no major changes in community profiles in pesticide amended environments compared to non-amended controls unless the compound is added at unrealistic high loading rates (Sniegowski et al., 2011a, 2011b; Bers et al., 2013b; Dealtry et al., 2016). A recent metagenomic analysis by Fang et al. (2014) supports this. The study revealed the presence of pesticide degradation genes in freshwater and marine sediments, but no information was recovered about their genetic context. Therefore, novel 'targeted metagenomic' approaches are required to collect sequence information on specific subsets of metagenomes (Suenaga, 2012). In this study, we present a novel culture-independent approach to acquire a better understanding of the gene functions carried by IS1071 in the environment and the role of IS1071 in microbial community genetic adaptation, beyond the information based on cultured isolates. The approach uses long-range PCR (LR-PCR) combined with NGS that recovers and identifies the accessory genes of IS1071 composite transposons in environmental DNA (eDNA). The LR-PCR uses primers that target the tnpA gene of
IS1071 with primer sequences that are directed outward of the IS element in order to amplify the intermediate DNA between two IS1071 elements. The LR-PCR method was applied on agricultural soil treated with the herbicide linuron and the same untreated control soil for comparative purposes. Similarly, the method was applied on material from an on-farm BPS in operation and on artificial pristine BPS material. We hypothesized that DNA recovered by our approach is enriched in pesticide catabolic genes in pesticide-exposed environments compared to the control environments.

\section{Results}

Optimization of a LR-PCR to recover accessory genes associated with IS1071 composite transposons from eDNA

To design suitable primers for amplification of IS1071 composite transposon accessory genes by means of LR-PCR, alignment and clustering of available IS1071 sequences was performed. Clustering of the sequences showed two main subtypes of IS1071 (subtype I and subtype II), with IS1071 subtype 1 representing the main fraction (80 of the 91 sequences; Supporting Information Fig. S1). Primers were designed and degenerated such that they recognized both IS1071 subtypes and matched all 91 sequences. LRPCR was optimized using IncP-1 plasmids containing IS1071 composite transposons with different accessory lengths (from 3.7 to $32.9 \mathrm{~kb}$ ) as templates (Table 1). Using a 16-min elongation time, expected amplicons between 3.5 and $18 \mathrm{~kb}$ were recovered with only minor a-specific amplification. Multiple targets were simultaneously recovered as shown with plasmid pADP-1, carrying two IS1071 accessory genes regions (Supporting Information Fig. S2), and with a mixture of pUO1 and pADP-1 with a total of three accessory genes regions (data not shown). However, using plasmid pl2, containing several IS1071 composite transposons, only the smaller $3.7 \mathrm{~kb}$ region was recovered and not the larger $24.8 \mathrm{~kb}$ segment. This suggests that an elongation time of $16 \mathrm{~min}$ recovers amplicons with sizes up to $20 \mathrm{~kb}$ (data not shown). Increasing the elongation time up to 33 min improved amplicon length but also resulted in amplification of plasmid backbone regions, as observed by the amplification of a $32.9 \mathrm{~kb}$ backbone region when plasmid pEST4011 was the template (data not shown). As a proof of concept, LR-PCR was performed on high molecular weight eDNA isolated from BPS Kortrijk material to which a 10 -fold dilution series of $E$. coli containing plasmid pNB8c was added. The identity of the $15.1 \mathrm{~kb}$ amplicon of pNB8c, containing the dcaRQTA1A2BC gene cluster, was confirmed by Southern blot hybridisation using $d c a Q$ as a probe. Amplicons of the expected size (in addition to amplicons originating from endogenous IS1071 accessory gene 
Table 1. Plasmids used in this study.

\begin{tabular}{|c|c|c|c|c|c|}
\hline Plasmid & Host & Size (kb) & $\begin{array}{l}\text { Size IS1071 accessory regions (bp) } \\
\text { (expected size of LR-PCR amplicon) }\end{array}$ & Relevant characteristics & Accession number \\
\hline \multicolumn{6}{|l|}{$\operatorname{lnc} P-1 \beta$} \\
\hline pNB8c & Escherichia coli & 60 & 15097 & $d c a A 1 A 2$ & JF274990 \\
\hline pUO1 & Delftia acidovorans & 67 & 5316 & $\mathrm{dehH} 1 \mathrm{H} 2$ & AB063332 \\
\hline pAKD18 & Pseudomonas putida & 67 & 12714 & $\mathrm{Hg}^{\mathrm{R}}$ & JN106169 \\
\hline pl2 & Escherichia coli & 84 & 3 746; 24 809; & $\mathrm{Hg}^{\mathrm{R}} ; d c a A 1 A 2$ & JF274989 \\
\hline $\begin{array}{l}\text { pADP-1 } \\
\text { IncP-1 } 1 \delta\end{array}$ & Escherichia coli & 109 & $9107 ; 11324$ & $\mathrm{Km}^{\mathrm{R}} ;$ atzA & U66917 \\
\hline 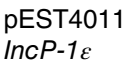 & Alcaligenes xylosoxidans & 77 & 43198 & tdfA & AY540995 \\
\hline pEMT3 & Escherichia coli & 63 & 17917 & $\mathrm{Km}^{\mathrm{R}} ; t f d A$ & JX469827 \\
\hline
\end{tabular}

For each of the plasmids their relevant characteristics and expected IS1071 LR-PCR amplicons are given. Abbreviations: $\mathrm{Km}^{\mathrm{R}}$, kanamycin resistance; $\mathrm{Hg}^{\mathrm{R}}$ : mercury resistance; atzA: Atrazine chlorohydrolase; dcaA1A2: Dichloroaniline dioxygenase; dehH1H2: Haloacetate dehalogenases; $t f d A$ : $\alpha$-ketoglutaric acid dioxygenase.

clusters) were obtained as long as $10^{4}$ copies of pNB8c per gram of material or more were present (Fig. 1). Diluting the eDNA extract 10-fold improved amplification while high concentrations of pNB8c resulted in the less efficient recovery of endogenous targets.

\section{Size range of IS1071 accessory genes in environmental samples as determined by $L R-P C R$}

The optimized LR-PCR was used to determine the diversity of IS1071 composite transposon accessory genes in two types of environments. The first environment was the matrix of a BPS in operation at a farm near the city of Kortrijk, Belgium that receives a high load of various pesticides (BPS Kortrijk). Samples analysed were taken in March 2011 before the start of the spraying season, during the spraying season in July and September 2011, and after shutting down its operation in December 2011. As a non-contaminated BPS control, a mixture of materials used in BPS mimicking non-treated BPS material (BPS pristine) was analysed in parallel. In advance to the LR-PCR, the relative abundance of IS1071 was determined in the BPS Kortrijk matrix by means of QPCR targeting tnpA and was found to be high throughout the season. Although there was merely a threefold change in abundance between samples taken in the middle of the
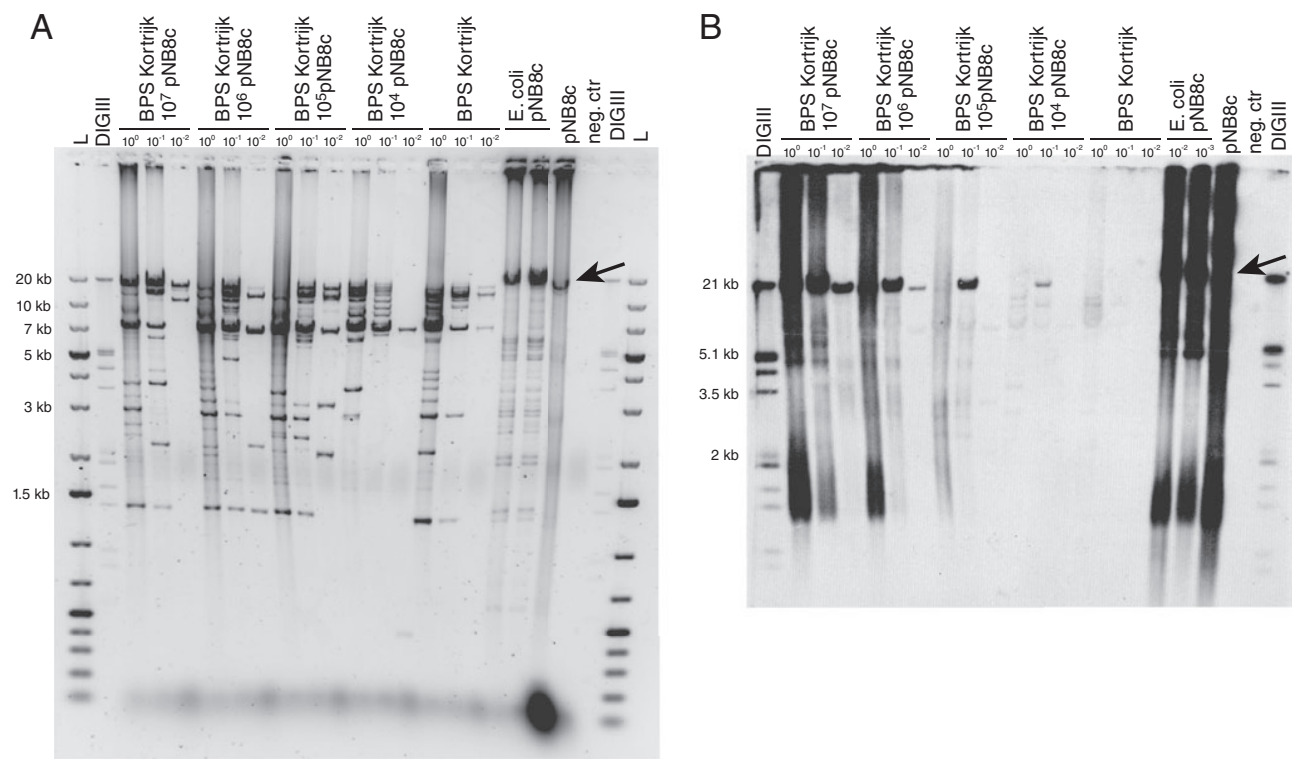

Fig. 1. Recovery of IS1071 accessory gene LR-PCR amplification products from BPS Kortrijk matrix samples spiked with different amounts of Escherichia coli containing plasmid pNB8c as indicated. The actual pNB8c copy numbers were determined using real-time PCR quantifying the tnpA gene. LR-PCR was performed on three 10-fold dilutions (indicated above the lanes) of the corresponding eDNA extract. Positive controls included both genomic DNA extracted from $E$. coli containing pNB8c and purified pNB8c plasmid DNA.

A. Agarose gel electrophoresis of recovered amplicons.

B. Southern blot hybridization with $d c a Q$ as probe. As negative control (neg. ctr), a non-template control was included in the LR-PCR. A regular

(L) and a digoxigenin labelled (DIGIII) size marker were used to estimate amplicons sizes. 
spraying season (July and September) and samples from March and December, this difference was significant (ANOVA; $p<0.05$; Tukey's test; Supporting Information Fig. S3). The second environment was agricultural soil (soil L) sampled from a previously reported soil microcosm (SM) experiment in which the soil was treated with tap water supplemented (microcosms 'L SM A', 'L SM B' and 'L SM C) or not-supplemented (microcosms 'W SM D', 'W SM E' and 'W SM F) with the phenylurea herbicide linuron (Bers et al., 2013b) for 491 days. In microcosm 'L SM B', feeding with linuron was replaced by only tap water from day 285 till day 491. Samples that were analysed were those taken at the end of the experiment at day 491. Linuron treatment of soil $L$ was previously shown to increase the numbers of IS1071 gene copies substantially (Dunon et al., 2013).

For the LR-PCR method, the size range of recovered amplicons was used as a first measure of diversity. In the BPS Kortrijk samples, the amplicon sizes ranged between 5 and $20 \mathrm{~kb}$. Profiles depended on the sampling position and time of sampling which is explained by the large matrix heterogeneity in such systems. On the other hand, many common bands can be recognized between samples (Fig. 2A). In contrast, amplicons originating from eDNA from BPS pristine were around $10 \mathrm{~kb}$ in length, with a less diverse size range compared to BPS Kortrijk (Fig. 2B). For the agricultural soil, both replicate microcosms treated with linuron till day 491 showed similar LR-PCR amplicons with sizes between 7 and $20 \mathrm{~kb}$. Interestingly, no amplicons were recovered from SM replicates that did neither receive linuron nor from the L SM B replicate for which linuron treatment was ceased from day 285 (Fig. 2C).

\section{NGS analysis of metagenomic LR-PCR amplicons: general observations}

LR-PCR amplicons from selected samples were analysed by NGS as a proof of concept. The selected samples included a BPS sample from the September sampling campaign (compartment 4) amid the pesticide spraying season showing a high abundance of IS1071 copies, soil from linuron microcosm L SM A
A

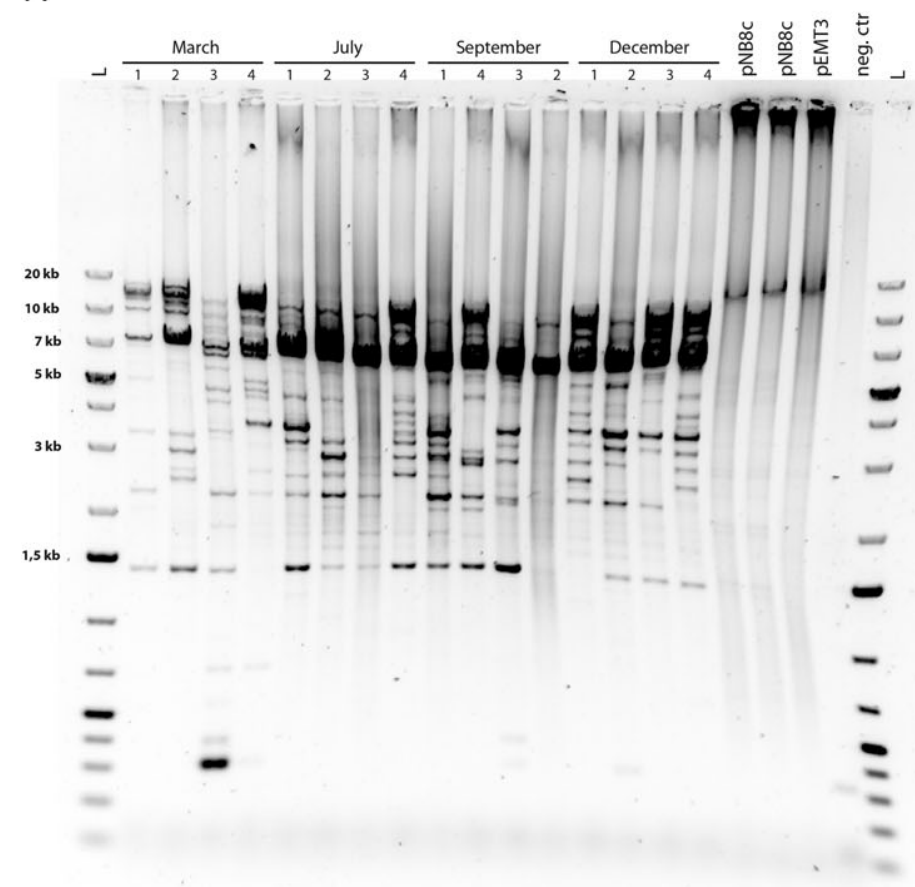

B

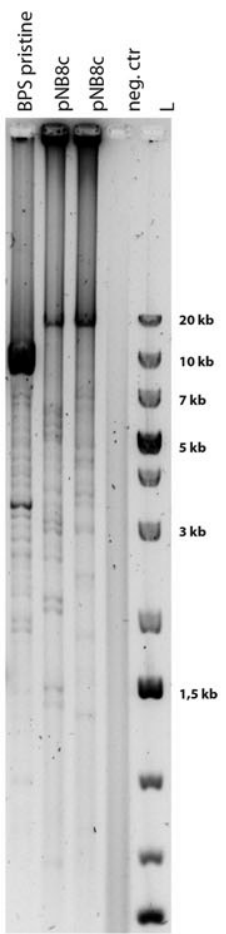

C

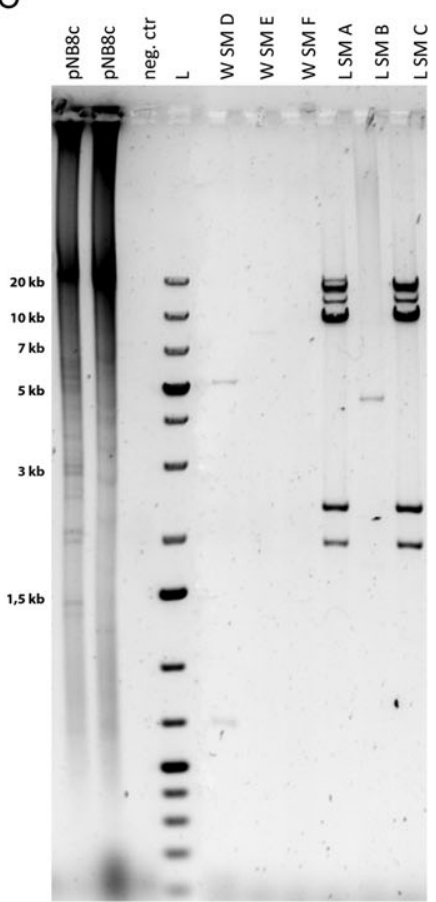

Fig. 2. Agarose gel electrophoresis visualization of IS1071 accessory gene LR-PCR amplicons recovered from BPS Kortrijk, BPS pristine and the linuron treated soil microcosm experiment.

A. Samples from BPS Kortrijk were taken in the course of the agricultural season of 2011 in March, July, September and December. At each time point, high molecular weight eDNA was isolated from four samples taken at different locations (compartments 1-4) of the BPS and used as a template for LR-PCR.

B. High molecular weight eDNA was isolated from a freshly made pristine BPS setup and used as a template for the LR-PCR.

C. High molecular weight eDNA was isolated at day 491 of incubation from all microcosm setups and used as a template for the LR-PCR. Different treatments with and without linuron were performed in triplicate: (i) discontinuous irrigation with sterile tap water (W SM D, W SM E and W SM F) and (ii) discontinuous irrigation with sterile tap water containing $60 \mathrm{mg} \mathrm{I}^{-1}$ linuron (L SM A and L SM C). In microcosm L SM B, after 285 days, linuron supply was ceased and instead sterile tap water was added. Plasmid DNA of pNB8c and pEMT3 carrying IS1071 composite transposons were included as positive controls with expected amplicon sizes of respectively 15.1 and $17.9 \mathrm{~kb}$. A non-template control was included as negative control (neg. ctr). To estimate amplicon sizes a size marker (L) was included. 
representative for the 491 days of continuous linuron application and the BPS pristine sample. Results from the assembly into contigs of HiSeq 2000 reads using Meta-Velvet and Velvet were highly similar for the same $\mathrm{k}$-mer value. Since the k-mer value applicable in MetaVelvet was limited $(\leq 63)$ at the time of assembly, final assemblies were done with Velvet with k-mer value of respectively 65,73 and 87 . Results are shown in Table 2. A number of contigs, size ranges of contigs and total unique sequence content varied between the samples, with BPS Kortrijk yielding the most contigs (316) and the highest unique sequence content (662 kb). Overall, sizes of contigs ranged between 0.2 and $18.2 \mathrm{~kb}$. The lowest amount of sequence information was recovered from BPS pristine. IS1071 sequences were identified at one or both contig boundaries in $30 \%, 20 \%$ and $50 \%$ of the contigs of BPS Kortrijk, L SMA and BPS pristine, respectively and several contigs (with sizes between 1.0 and $17.2 \mathrm{~kb}$ ) displayed IS1071 IR sequences at both ends (Table 2). Based on the IR sequence, the majority of IS1071 sequences were allocated to subtype 1 IS1071 elements (Table 2). Two contigs (contig 75 and 164) from BPS Kortrijk flanked at both ends by IS1071 IRs, carried as well a subtype 1 as a subtype 2 IS1071 element. The $18 \mathrm{~kb}$ contig 255 of BPS Kortrijk was flanked by an IS1071 element with a partial tnpA gene with only $87 \%$ nucleotide (nt) identity to the representative IS1071 subtype 1 of the haloacetate catabolic plasmid pUO1 (Sota et al., 2003), although the deduced partial transposase shares $94 \%$ amino acid (aa) identity with TnpA of pUO1. Similarities with the IS1071 subtype 2 of the

Table 2. Summary of the analysis of the NGS data obtained from the LR-PCR amplicons recovered from the three studied ecosystems.

\begin{tabular}{llll}
\hline & $\begin{array}{l}\text { BPS } \\
\text { Kortrijk }\end{array}$ & L SM A & $\begin{array}{l}\text { BPS } \\
\text { pristine }\end{array}$ \\
\hline Clean sequencing data (Mbp) & 873 & 503 & 535 \\
Assembled sequence data (kb) & 662 & 131 & 44 \\
Contigs & 316 & 73 & 17 \\
Size range contigs (kb) & $0.2-18.2$ & $0.2-14.0$ & $0.2-10.7$ \\
$\begin{array}{l}\text { Contigs with IS1071 IR } \\
\quad \text { contigs with 2 IRs) }\end{array}$ & $105(18)$ & $16(2)$ & $9(3)$ \\
\% IS1071 subtype 1 & 89.1 & 94.4 & 100 \\
ORFs & 742 & 158 & 44 \\
ORFs with KO & 193 & 39 & 12 \\
ORFs with known function & 393 & 88 & 28 \\
$\quad$ BLASTp [nr] & & & \\
ORFs with HMM & 517 & 94 & 26 \\
\hline
\end{tabular}

Reported is the amount of data used after quality filtering of the sequencing reads, the total amount of sequence data after assembly, the number of contigs, size range of the contigs, number of contigs with IS1071 IRs and the occurrence of IS1071 subtype 1. Also, the number of predicted open reading frames (ORFs) by RAST is given. Annotations of the ORFs were made by assigning either a KO number using blastKOALA, similar known protein function using BLASTp or the retrieval of Hidden Markov Models (HMM) using hmmscan. 4-chloronitrobenzene catabolic pCNB-1 (Ma et al., 2007) were only $74 \%$ and $77 \%$ nt and aa identity, respectively.

\section{Identification of accessory genes on metagenomic IS 1071 LR-PCR amplicons}

To obtain a first overview of the functions encoded by the contigs, ORFs were predicted by RAST (total numbers are shown in Table 2), KEGG Orthology (KO) identifiers were assigned to the deduced protein sequences to classify the proteins into functional categories (Fig. 3). A KO number was assigned to $26 \%, 25 \%$ and $27 \%$ of the predicted proteins recovered from BPS Kortrijk, L SM A and BPS Pristine, respectively (Table 2). However, many of the ORFs were assigned a $\mathrm{KO}$ that was not linked to a specific functional category, i.e. $23 \%$ (44/193), $25 \%$ (7/39) and $27 \%$ $(5 / 12)$ of the assigned KO of respectively BPS Kortrijk, L SM A and BPS pristine. Predominant functional categories present in the BPS Kortrijk contigs included xenobiotics biodegradation and metabolism (46 ORFs), amino acid metabolism (40 ORFs) and carbohydrate metabolism (23 ORFs). Predominant categories in the contigs from $L$ SM A were translation (12 ORFs) and xenobiotics biodegradation and metabolism (4 ORFs). Most predicted protein functions found in the BPS pristine contigs were amino acid metabolism ( 3 ORFs), xenobiotics biodegradation and metabolism (3 ORFs) and carbohydrate metabolism (3 ORFs). KOs from BPS Kortrijk and BPS pristine were classified in more than one category. Especially KOs classified in the amino acid metabolism were also classified in the xenobiotics metabolism and carbohydrate metabolism. For instance, for BPS Kortrijk, seven ORFs were classified in the amino acid, carbohydrate and xenobiotic metabolism. Those seven ORFs were annotated as either an acetyl-CoA C-acetyltransferase or an aldehyde dehydrogenase, involved in more downstream reactions of catabolic pathways. In contrast, ORFs that were solely categorized to xenobiotic metabolism included enzymes catalysing upstream reactions in xenobiotic degradation pathways, e.g. aromatic ring-hydroxylating dioxygenases and monooxygenases. Besides metabolic functions, BPS Kortrijk showed proteins associated with membrane transport and cellular community (Fig. 3) of which 15 ORFs were annotated in both categories being related to $\mathrm{ABC}$-transporter systems and quorum sensing. Moreover, two ORFs were categorized in the antimicrobial resistance category.

A more in-depth analysis of the predicted protein sequences was done by examining the presence of Hidden Markov Models (HMM) using hmmscan and protein similarities using BLASTp against the UnitProtKB/SwissProt database and non-redundant protein database (Tables 2 and 3 and the Supplementary Annotation File). Proteins were recognized as such on 215, 50 and 


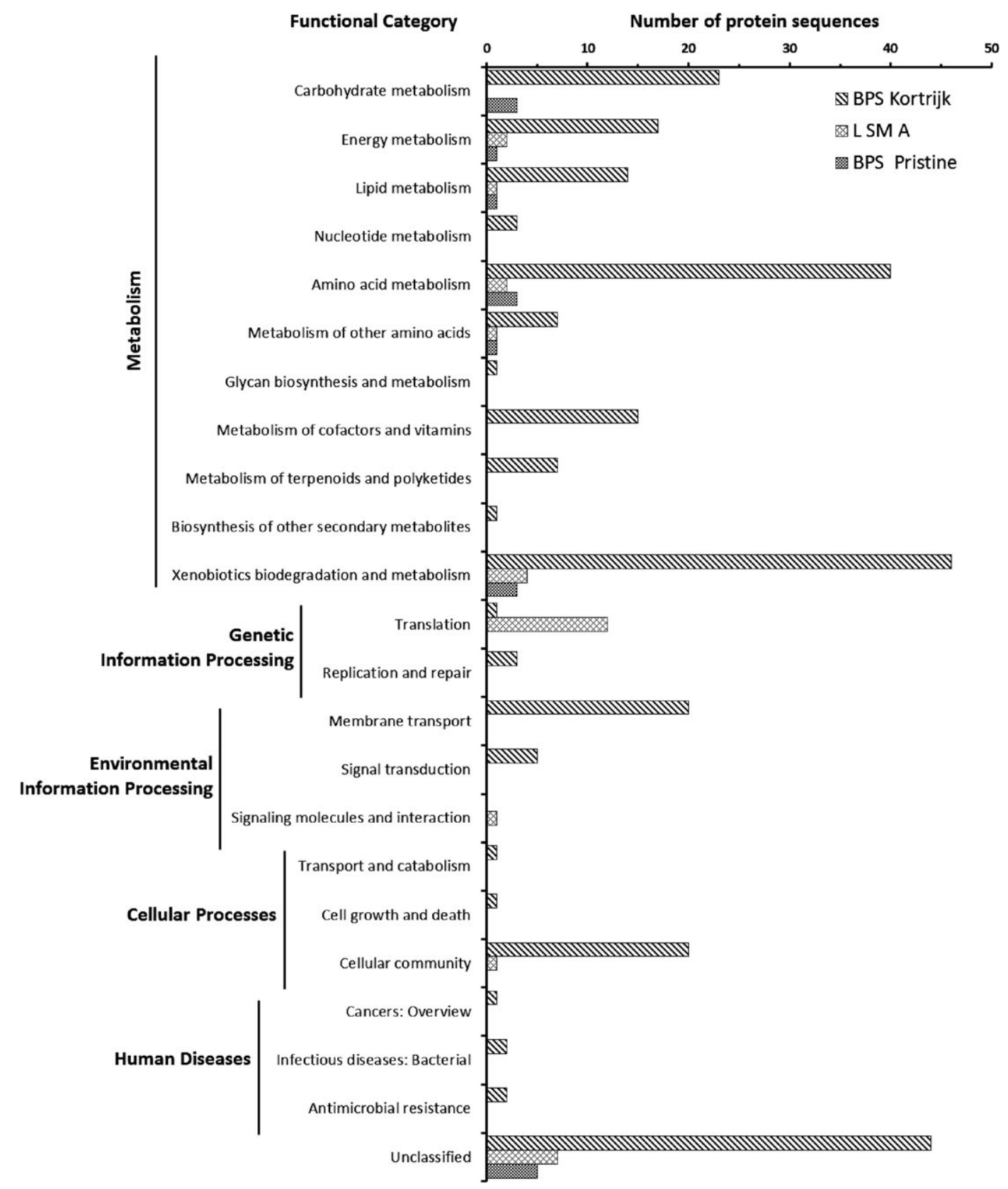

Fig. 3. KEGG orthology (KO) classification of predicted proteins identified on the sequenced IS1071 LR-PCR amplicons of BPS Kortrijk, L SM A and BPS pristine. BlastKOALA (KEGG Orthology and Links Annotation) was used to assign KOs to the predicted proteins based on protein similarities using the reconstruct pathway output. Numbers represent the number of protein sequences that were assigned to that specific KO category. Total numbers of proteins assigned with a KO annotation were 262 (35.3\%) for BPS Kortrijk. 51 (32.3\%) for L SM A and 15 (34.1\%) for BPS pristine.

11 contigs in BPS Kortrijk, L SM A and BPS Pristine respectively. In total, $41 \%, 26 \%$, and $45 \%$ of the contigs originating from BPS Kortrijk, L SM A and Pristine BPS, respectively contained at least one ORF that encodes a putative function showing substantial aa similarity to catabolic enzymes (Supplementary Annotation File). The catabolic functions included more upstream functions of catabolic pathways as well as more downstream functions. Upstream functions included aromatic ring- hydroxylating Rieske dioxygenases or monooxygenases (17 ORFs in BPS Kortrijk, 3 ORFs in L MS A and 0 ORFs in BPS Pristine), taurine/ $\alpha$-ketoglutarate dioxygenases ( 6 in BPS Kortrijk and 0 in L MS A), enzymes that act on $\mathrm{N}$-containing functional groups like amidohydrolases/amidases (10 ORFs in BPS Kortrijk, 2 ORFs in L SM A), nitrile hydratases ( 3 ORFs in BPS Kortrijk) and nitrilases (1 ORF in BPS Kortrijk) and enzymes involved in chlorine removal (2 contigs in BPS Kortrijk). Several of these 
could be directly (with more than $99 \%$ aa identity) linked with known enzymes involved in pesticide degradation like HyIA (contig 290 in BPS Kortrijk and contig 22 in L SM A) catalysing linuron hydrolysis (Bers et al., 2013a) and AtzA (contig 260 in BPS Kortrijk) catalysing atrazine chlorine hydrolysis (de Souza et al., 1998). Others showed moderate similarity to known pesticide biodegradation enzymes like TfdA/RdpA (contigs 132, 205, 265, 298 and 302 in BPS Kortijk) and TfdB (contig 231 in BPS Kortrijk) involved in phenoxy herbicide biodegradation (Fukumori and Hausinger, 1993; Ledger et al., 2006; Müller et al., 2006). Downstream pathway enzymes included aromatic ring cleavage enzymes and enzymes that are involved in the further conversion of the (substituted) aromatic cleavage products to Krebs cycle intermediates. Similar to the upstream catabolic functions, several of these proteins could be directly linked to pesticide biodegradation like proteins encoding chloroanaline dioxygenase (contig 250 in BPS Kortrijk and contig 23 in L SM A) involved in the degradation of several pesticide groups including phenylurea herbicides such as linuron (Bers et al., 2013a) and enzymes of the modified ortho-cleavage pathway for chlorocatechol degradation (contigs 70, 117, 293 and 309 in BPS Kortrijk and contigs 21 and 33 in L SM A) for instance involved in degradation of chlorinated aromatic pesticides (Kumar et al., 2016). Other downstream pathway enzymes were enzymes that could be linked to lipid (like cholesterol) and fatty acid metabolism (e.g. aldehyde dehydrogenase and acetylCoA transferase), a downstream pathway that is also employed in pesticide biodegradation.

Several contigs showed ORFs that together composed a recognizable catabolic holoenzyme or even a complete or partial catabolic pathway. Examples in the BPS Kortrijk sample are contigs 5, 44, 117, 250, 293 and 318. Contig 5 contained two ORFs that encode the $\alpha$ and $\beta$-subunit of a non-corrinoid cobalt nitrile hydratase holoenzyme forming a functional nitrile hydratase as well as an ORF that encodes a putative cobalt transporter, which might be involved in the acquisition of cobalt for the nitrile hydratase (Kobayashi and Shimizu, 1998). Contig 44 contains next to an ORF showing homology to nitrilases, a cluster of genes that together encodes all components of a twosubunit urease as well as accessory proteins that participate in the regulation of nickel delivery and maturation of the urease (Lee et al., 1992). Contig 117 contains all the ORFs required for a functional chlorocatechol orthocleavage pathway (Bers et al., 2013a), contig 250 for a functional (chloro-)aniline dioxygenase multicomponent enzyme (Król et al., 2012), contig 293 for a pathway degrading a sulfonated aromatic (Halak et al., 2007) and contig 318 for a 4-chlorobenzoate-CoA ligase dehalogenating 4-chlorobenzoate (Layton et al., 1992). In L SM A, contig 21, carries, like contig 117 in BPS Kortrijk, all ORFs required for a functional chlorocatechol ortho-cleavage pathway while contig 23, like contig 250 in BPS Kortrijk shows parts of a (chloro-)aniline dioxygenase holoenzyme. In the BPS pristine sample, no catabolic functions could be directly assigned to any of the putative catabolic ORFs.

Non-catabolic proteins were recognized on most of the contigs, including those containing catabolic ORFs. A majority of these ORFs showed homology at the aa level with regulatory proteins or transport proteins and in many cases homology was found with regulatory (like LysR, ICIR and MarR family proteins) and transport proteins involved in aromatic catabolism indicating that they might be involved in substrate uptake for and regulation of the neighbouring catabolic genes. A particular gene function that was identified in a large number of contigs in all three samples was a gene function whose translation product showed identity with extra-cytoplasmic solute receptors belonging to the Bug family. Similar ORFs with unknown function were previously identified in gene clusters encoding the modified chlorocatechol ortho-cleavage pathway, a central pathway in chloroaromatic biodegradation (van der Meer et al., 1991; Shin and Spain, 2009). Other non-catabolic functions were related to MGEs. A vast amount of ORFs coded for putative IS element transposase functions, most of which belonged to unknown families, but some belonged to the IS21, IS4 and IS66 families. Other MGE related functions were putative plasmid backbone functions. Most of these plasmid backbone gene functions are gene functions such as $\mathrm{KIcA}, \mathrm{KIcB}, \mathrm{KorC}, \mathrm{KleA}$, KleE and KleF encoded by the replication module of IncP-1 plasmids. Highest identity was found with those of IncP-1 plasmids of the IncP- $\beta 1$

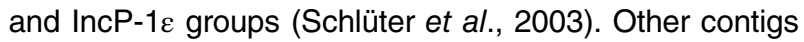
showed plasmid backbone functions that were not related to IncP-1 plasmids. For instance, two ORFs in the BPS Kortrijk contig 144 showed high aa identity with the plasmid mobilization proteins MobL and MobS of the IncQ related Thiobacillus ferrooxidans plasmid pTF1 (Drolet et al., 1990). Interestingly, with a few exceptions, contigs carrying transposase functions and especially plasmid functions did not contain ORFs with other functions (Supporting Information Table S1). Other ORFs that could be linked to non-catabolic functions were genes showing similarity at the aa level with multidrug efflux transporters (contig 1 in BPS Kortrijk, 64\%), proteins involved in mismatch repair (contig 25 in BPS Kortrijk, MutS, 99\%), transglycosylase protein (contig 8 in BPS Kortrijk, 39\%; contig 39 in L MS A, 33\%) and lysis protein (contig 37 in L MS A, muramidase, 38\%), ribosomal-proteins (r-proteins; contigs 43 and 44 in L MS A, 48-71\%), UV protection protein (contig 26 in BPS Kortrijk, IpmB, 38\%), mutagenesis proteins (contig 26 in BPS Kortrijk, UmuC, 38\%), uncharacterized putative membrane proteins (contig 27 in BPS Kortrijk, 51\%; 
8 V. Dunon et al.

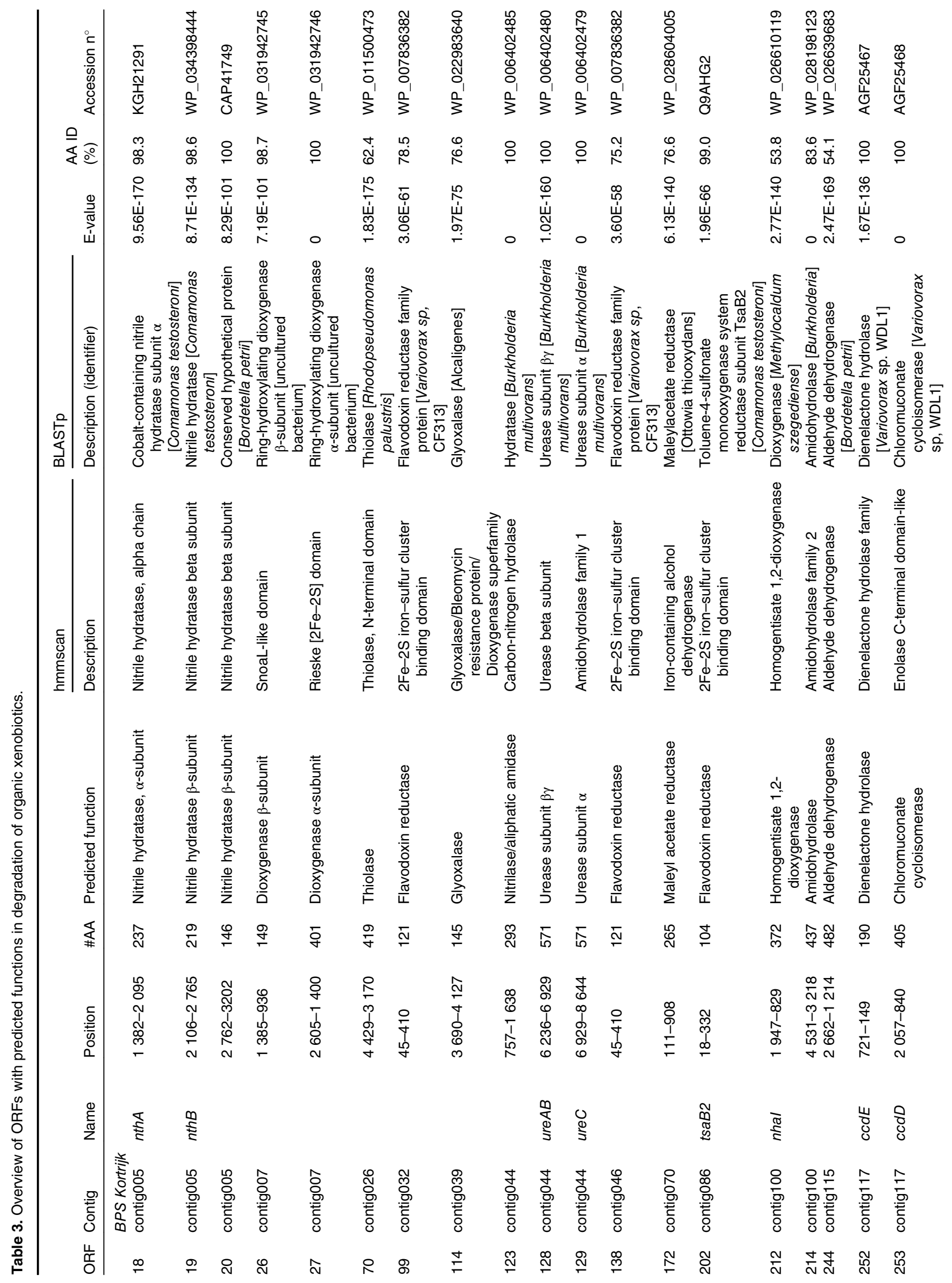




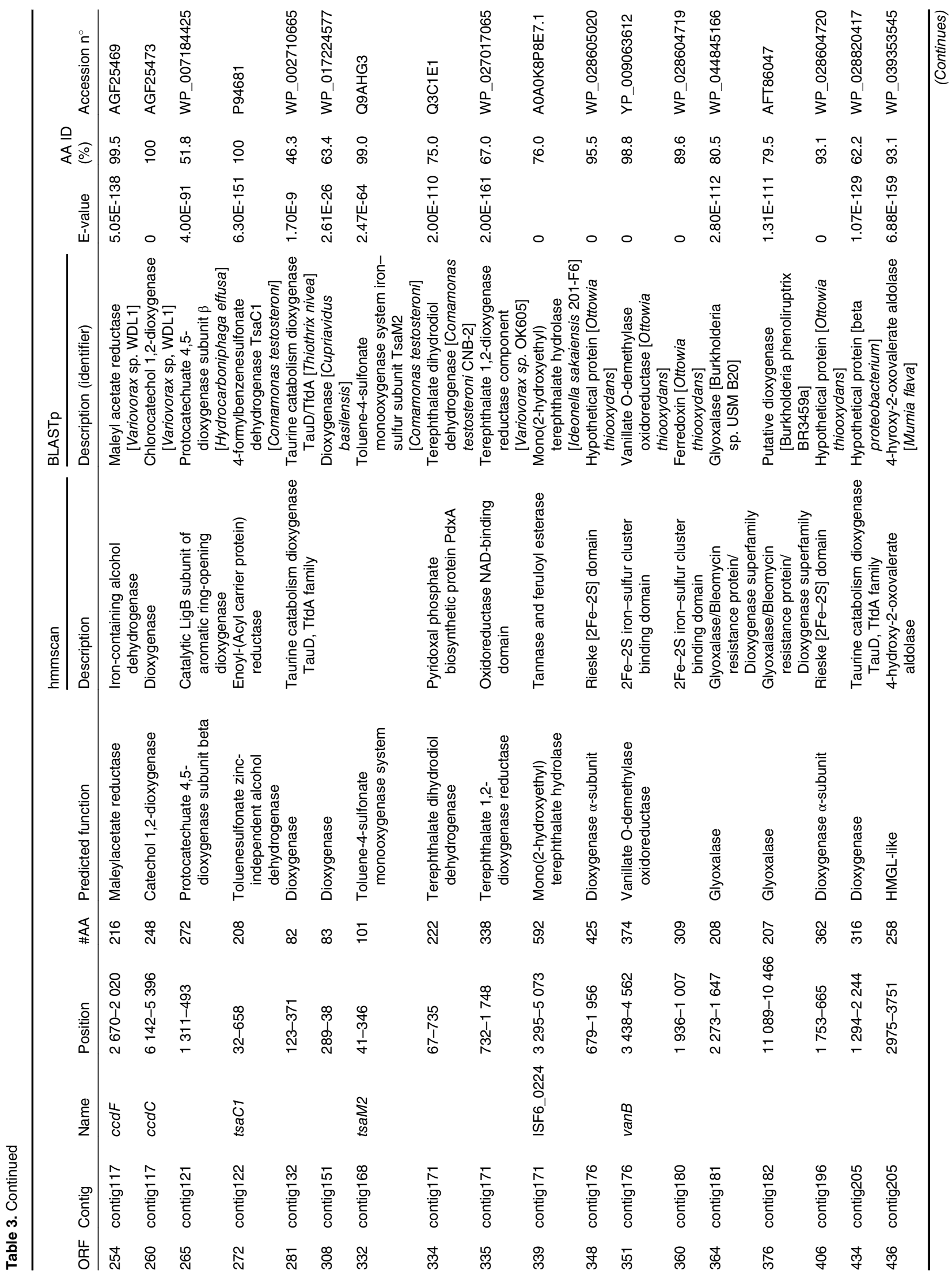


10 V. Dunon et al.

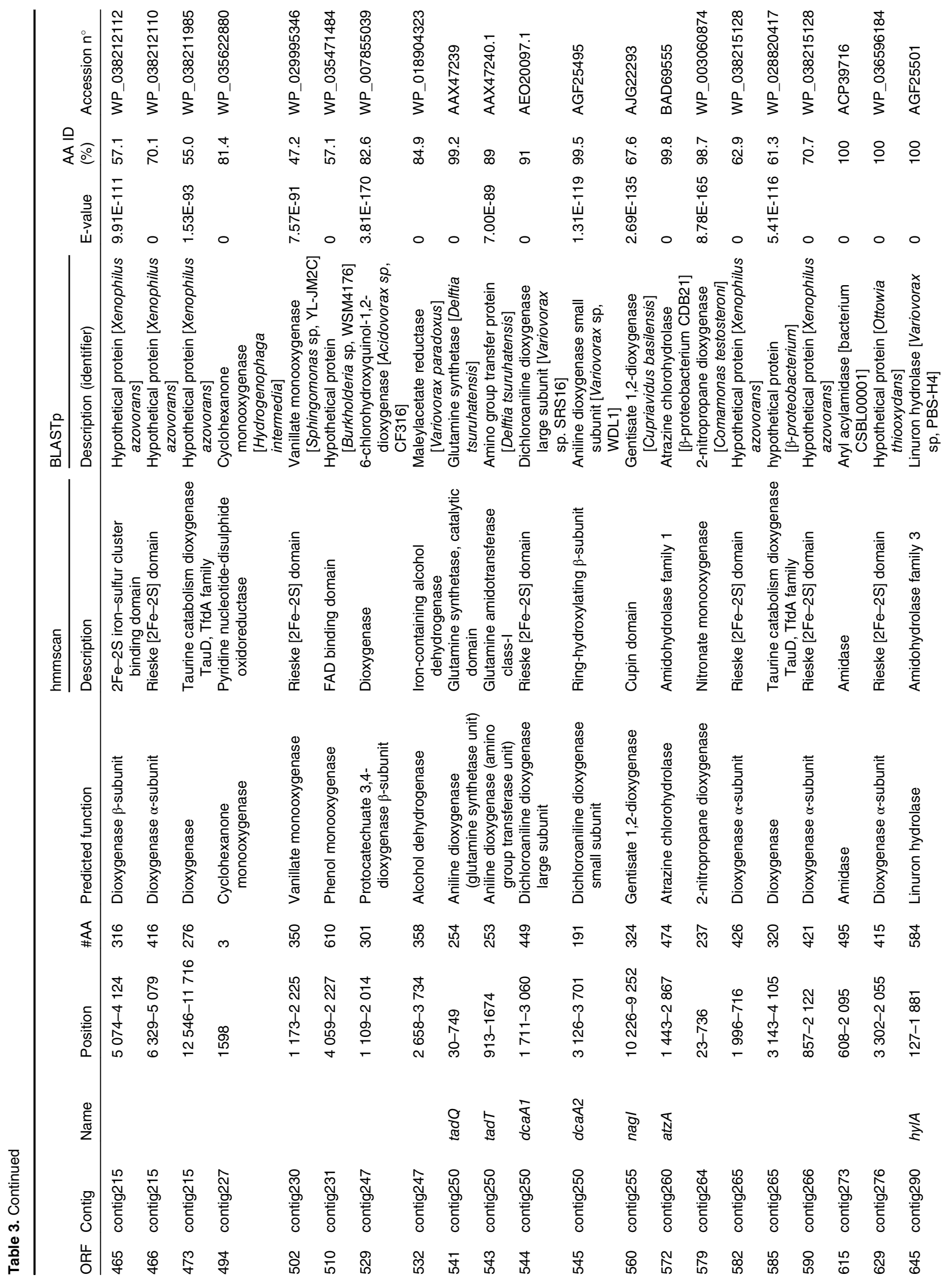




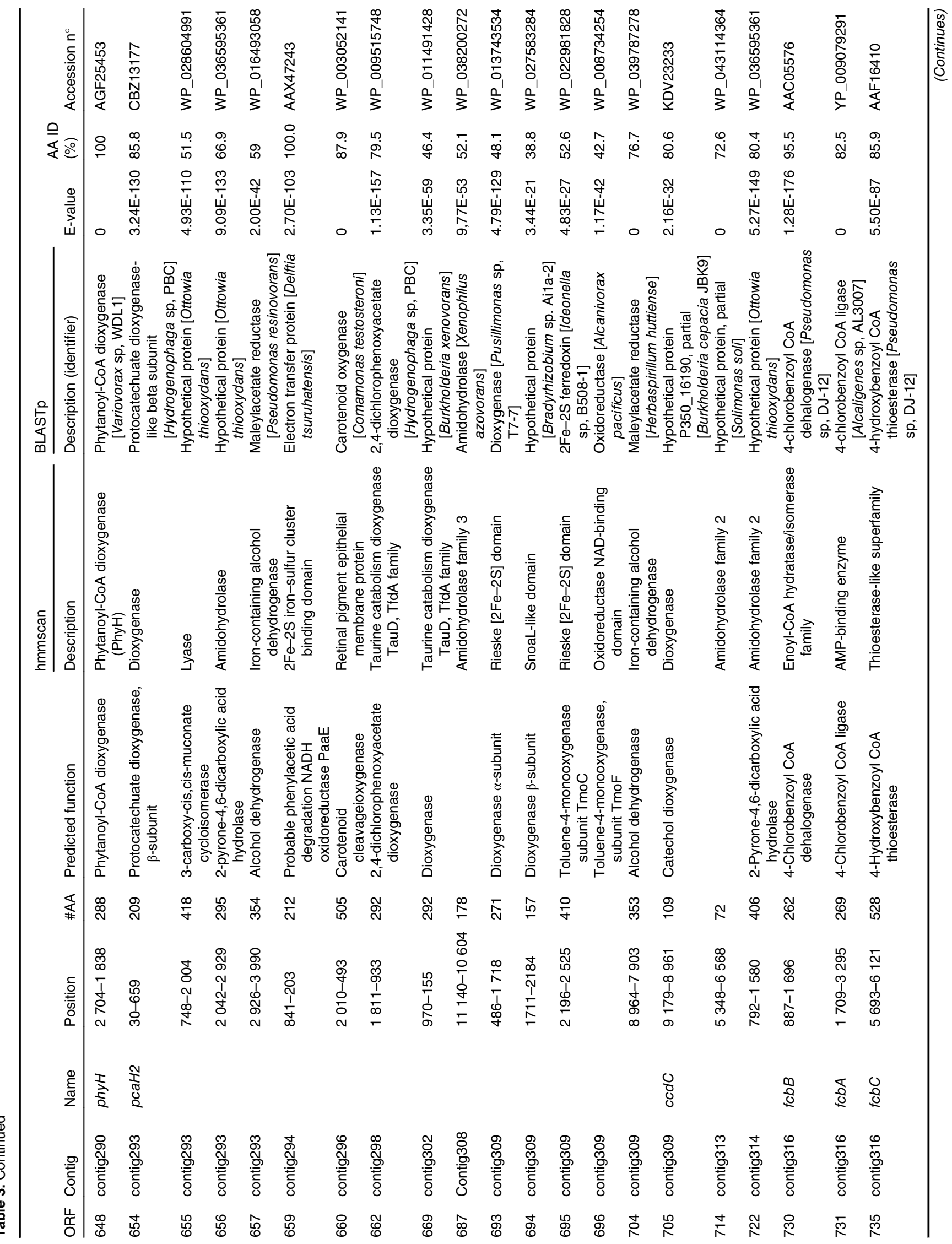




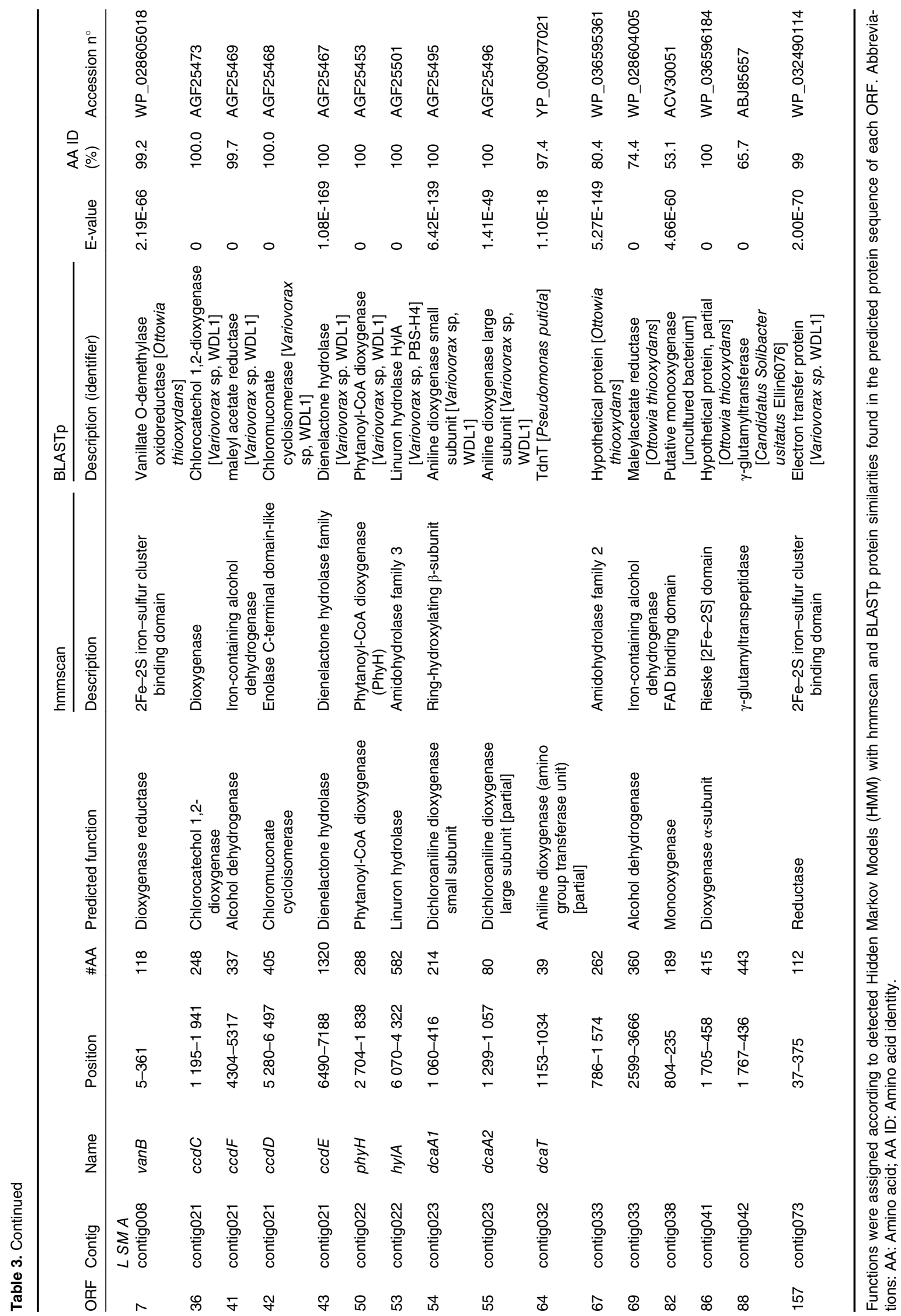


contig 85 in BPS Kortrijk, 52\%; contig 186 in BPS Kortrijk, 48\%), osmosis regulatory channel (contig 53 in L SM A, 62\%) mercury resistance regulator MerR (contig 260 in BPS Kortrijk, 46\%) and DNA repair (contig 275 in BPS, UvrB, $81 \%$,). A large part of the ORFs represented unknown proteins. Some contigs even consisted of only ORFs to which no function could be assigned (either being unknown or showing similarity to ORFs with unknown function).

\section{Genetic organization and synteny of metagenomic LR-PCR amplicons}

Mega-BLAST searches performed on the complete LR amplicon contigs against the NCBI nr-database provided insight into gene synteny between the LR-PCR contigs and available genomic information as well as between the different LR-PCR contigs. Some of these contigs encoded protein functions identified by the previous BLASTp analysis, and other short contigs carried incomplete genes. Forty-eight BPS Kortrijk contigs showed high synteny with more than $95 \%$ nt similarity over the full length with a sequence in the NCBI nr-database, of which 29 were plasmid-borne. Similarly, several contigs recovered from L SM A (24 contigs; 11 plasmid-borne) and BPS pristine (2 contigs; 1 plasmid-borne) showed significant synteny and high nt similarity with reported bacterial genome regions and especially plasmid regions. Identified plasmid-borne sequences included both plasmid backbone gene clusters and accessory gene clusters. Plasmid regions were particularly central control regions containing IncP-1 plasmid maintenance functions showing complete synteny with at least one reported IncP-1

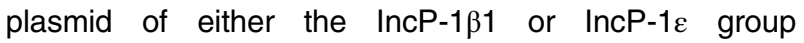
(Supporting Information Fig. S9). Similarly, the contigs that carried the hylA gene for linuron degradation (contig 22 in L SM A and contig 290 in BPS Kortrijk as well the contigs carrying the dichloroaniline degradation genes (contigs 294 and 250 in BPS Kortrijk; contig 23 in L SM A) and chlorocatechol degradation gene clusters (contig 117 in BPS Kortrijk and contig 21 in L SM A) showed complete synteny (with 99\% nt similarity) with corresponding IS1071 bordered (at both sites) catabolic regions in the linuron degrading Variovorax sp. WDL1 (Fig. 4A; Supporting Information Table S1). Moreover, also contigs 8 and 204 of BPS Kortrijk as well as contigs 39, 26 and 6 of L SM A corresponded to these regions (Fig. 4A; Supporting Information Table S1). Similarly, contig 260 carrying atzA showed complete synteny with the corresponding atrazine catabolic region of IncP-1 $1 \beta 1$ plasmid PADP-1, which is bordered by IS1071 elements at both ends (Fig. 4B; Supporting Information Table S1). Contig 7 of BPS Kortrijk was almost identical in nt sequence and organization with a IS1071 bordered (at one site) uncharacterized catabolic gene region on plasmids pAKD33 and pAKD15 (Supporting Information Table S1; Fig. 4C) encoding putative alpha and beta ringhydroxylating dioxygenase subunits (ORF26 and ORF27 on contig 7). Another part of the catabolic gene cluster located on PAKD15 was retrieved on contig 176 of BPS Kortrijk and contains two other putative dioxygenase genes (ORF348 and ORF351). Besides the contigs that encoded linuron hydrolysis, dichloroaniline degradation and chlorocatechol degradation, only two other regions were identified with substantial synteny between the BPS Kortrijk and L SM A amplicons. Contigs 41 and 5 showed nt identity and synteny with contig 276 of BPS Kortrijk while contigs 314 and 70 of BPS Kortrijk showed synteny with contig 33 of $L S M A$. These regions encoded for a putative dioxygenase (BPS Kortrijk, contig 276; L SM A, contig 41) and putative amidohydrolase (BPS Kortrijk, contig 314; L SM A, contig 33; Supporting Information Fig. S4; Table S2).

Synteny relationships with published genomes but based on less nt homology was explored by checking the BLASTp comparison results against the $\mathrm{nr}$ protein sequences for ORF clusters that show identical gene organizations as those found in the LR-PCR amplicons. Results are compiled in Supporting Information Table S3 while examples are shown in Supporting Information Fig. S8 for some contigs recovered from BPS Kortrijk, i.e. contig 5 containing a cobalt-containing nitrile hydratase cluster, contig 26 containing an unknown $\mathrm{ABC}$-transporter system and contig 44 containing a complete urea transport and hydrolysis cluster. Interestingly, while IS1071 bordered at least one of the junctions in syntenic regions that showed more than $95 \%$ nt identity and near perfect synteny, this often was not the case for the syntenic gene clusters that showed less nt sequence identity. A substantial fraction (around 60\%) of those however showed the presence of nearby IS elements (Supporting Information Table S3).

\section{Pesticide degradation and mineralization capacity}

Since genes involved in atrazine and linuron were recovered from the BPS samples, samples taken from the BPS Kortrijk at different time points during the agricultural season of 2011 were assessed for linuron mineralization and atrazine degradation. As a control, pristine BPS material was tested. All BPS Kortrijk samples showed mineralization of linuron and degradation of atrazine, while the control pristine BPS samples did not (Supporting Information Figs. S5 and S6).

\section{Discussion}

Accessory regions of IS1071 composite transposons were captured from complex microbial communities 
A

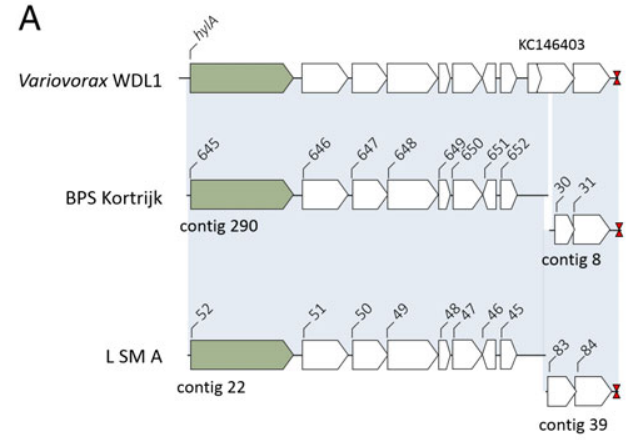

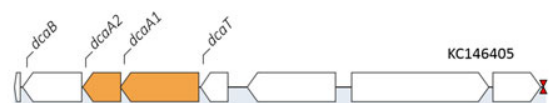

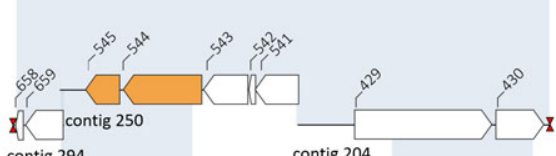

contig 294

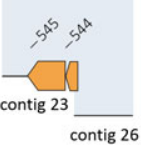

contig 204

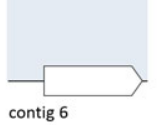

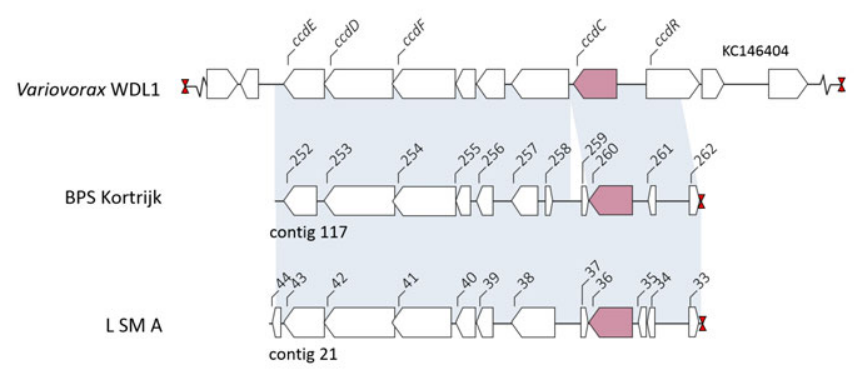

B

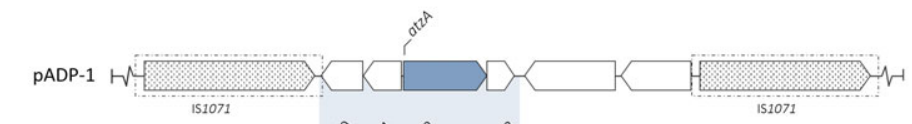

BPS Kortrijk
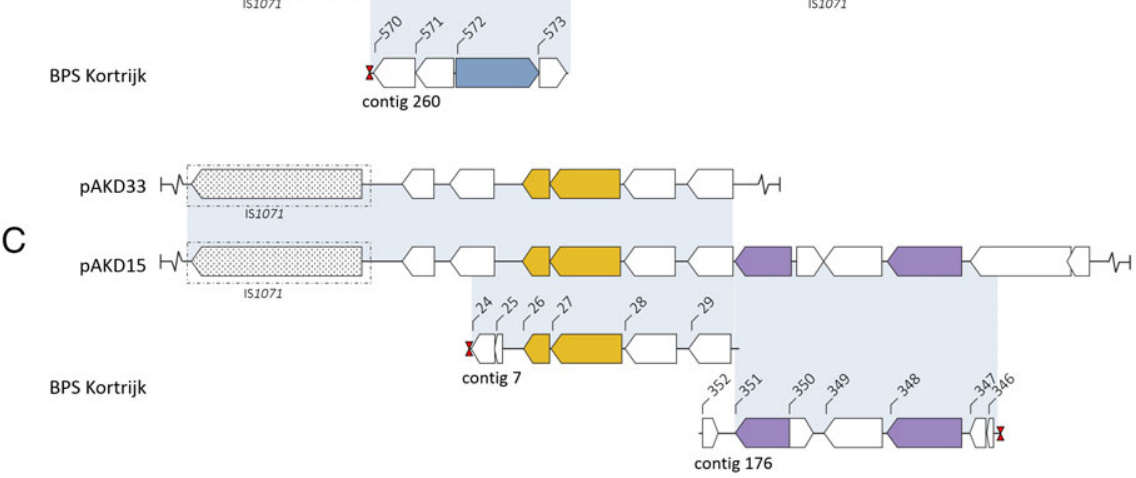

$\frac{1 \mathrm{~kb}}{\mathrm{X} \text { Remnant inverted repeat IS1071 }}$

Fig. 4. Nucleotide sequence similarity and synteny between selected contigs derived from the NGS of LR-PCR amplicons and relevant sequences in the nr-database. Sequence similarities with $99 \%-100 \%$ nucleotide identity as determined using BLASTn are shown by shaded regions.

A. Comparison of retrieved contigs of BPS Kortrijk and L SM A and catabolic regions of Variovorax sp WDL1 (accession numbers KC146403, $\mathrm{KC146404}$ and $\mathrm{KC146405).} \mathrm{Key} \mathrm{gene} \mathrm{functions} \mathrm{for} \mathrm{the} \mathrm{degradation} \mathrm{of} \mathrm{linuron} \mathrm{are} \mathrm{highlighted:} \mathrm{initial} \mathrm{linuron} \mathrm{hydrolase,} \mathrm{hylA} \mathrm{(green),}$ 3,4-dichloroaniline dioxygenase subunits, dcaA1A2 (orange) and the catechol 1,2-dioxygenase, ccdC (magenta).

B. Comparison of contig 260 of BPS Kortrijk with the IS1071 composite transposon of IncP-1 plasmid pADP-1 containing atzA (blue) responsible for the initial dechlorination step in the bacterial degradation of atrazine in Pseudomonas sp. ADP1.

C. Comparison of contigs 7 and 176 recovered from BPS Kortrijk with uncharacterized catabolic gene clusters present on plasmids pAKD15 and pAKD33. The region on pAKD33 includes genes encoding a putative alpha and beta ring-hydroxylating dioxygenase subunit corresponding to ORF26 and ORF27 (yellow) located on contig 7. The region on pAKD15 contains two additional putative dioxygenase related genes corresponding to ORF348 and ORF351 in contig 176 (purple).

without cultivation step to further elucidate the ecological function of IS1071 beyond the information known from cultured isolates. To this end, we developed a high sensitivity LR-PCR method that recovers long DNA fragments from high molecular weight eDNA. By applying this method on environmental samples with a record of regular pesticide exposure, we were able to capture known and potential novel xenobiotic catabolic gene functions, giving support to IS1071 being involved in the genetic adaptation of natural microbial communities.

LR-PCR to recover accessory regions of IS1071 composite transposons: opportunities and limitations

An LR-PCR method that combines selectivity/specificity and sensitivity to recover accessory regions of IS1071 
composite transposons was successfully developed. The method selectively recovered regions located between two IS1071 elements based on primers directed outward of IS1071. The LR-PCR primers were tailored to target two IS1071 subtypes, as the existence of two IS1071 subtypes was proposed by Ma et al. (2007) based on the analysis of a metal resistance/catabolic gene cluster on plasmid pCNB1. Our analysis of current available IS1071 sequences showed that the IS1071 subtype 2 group represents up to $10 \%$ of the IS1071 sequences and hence that subtype 2 is an important group that needs to be covered. Moreover, the same composite transposon can be bordered by two subtypes. Indeed, 10 of the 11 reported gene clusters that are flanked by IS1071 subtype 2 at one site are flanked by a subtype 1 IS1071 element at the other site (Boon et al., 2001; Dejonghe et al., 2002; Bers et al., 2011; Ma et al. 2007). Sequence analysis of the LR-PCR amplicons provided immediate proof of principle of selectivity of the method. Of the contigs $28 \%$ contained partial IS1071 IR sequences at least on one of the borders, implying that the contigs were truly carried by IS1071 based composite transposons. Moreover, contigs bordered by both IS1071 subtype 1 and subtype 2 were recovered. IS1071 subtype 1 was the dominant subtype in the three examined ecosystems which agrees with its dominance among reported IS1071 elements in the nt database. However, IS1071 subtype 2 elements were recovered in both the BPS Kortrijk and L SM A samples providing evidence for its ecological relevance. Interestingly, potentially a third IS1071 subtype was identified in this study showing most resemblance with subtype 1 IS1071 (87\% nt identity).

The size of the recovered amplicons is an important item in the method since IS1071 composite transposon accessory regions of up to $43 \mathrm{~kb}$ have been reported. Amplicons of up to $20 \mathrm{~kb}$ were efficiently recovered using our LR-PCR method. Increasing the elongation time resulted into larger amplicons but also into the amplification of unwanted plasmid backbone regions when plasmid DNA carrying IS1071 composite transposons was used as a template. As such, taking into account that IS1071 composite transposons are often carried by plasmids, the elongation time was set to $16 \mathrm{~min}$, limiting the accessory regions under study to $20 \mathrm{~kb}$. Analysis of the lengths of accessory regions bordered by IS1071 elements in the NCBI database suggests that around 34\% was excluded, assuming no bias in the database. However, even with the current protocol, $5.5 \%$ of the contigs consisted of plasmid backbone. Even though these amplicons are unintended, they also provide interesting information about the plasmid replicons that are carrying them. We found that the recovered plasmid backbone regions especially concerned regions from IncP-1 plasmids of the IncP-1 $\beta 1$ and IncP-1E subgroups (Tsuda et al., 2014). This is in agreement with IncP-1 plasmids found so far in isolates, confirming that these two IncP-1 subgroups are important carriers of IS1071 composite transposons. It further suggests that at least a fraction of the IS1071 and its associated accessory genes are located on plasmids and in particular on IncP-1 plasmids. IncP-1 plasmids have two major insertion hot spots for accessory genes (Supporting Information Fig. S10) including IS1071 composite transposons, i.e., in between the origin of replication (oriV) and the gene encoding the replication initiation protein (trfA) and in between the trboperon and traC (Sota et al., 2007). Therefore, backbone regions based on those insertion sites were expected to appear in our LR-PCR amplicons, but this was not the case. Instead, the central control region (re/E-kfrA), covering $k / c B A, k l e F E B A$ and korBAC, was amplified most frequently. In IncP- $1 \beta$ plasmid pB4, the location of the accessory genes deviates from other IncP-1 plasmids and is between traM and kfrC (Tauch et al., 2003). Amplification of the central control region can be explained by the simultaneous presence of IS1071 in the insertion sites traM-kfrC and oriV-trfA (Supporting Information Fig. S10). Hence, the frequent recovery of the central control region of IncP-1 might suggest that traM-kfrC, is a more important hot spot of insertion in IncP-1 plasmids than known from bacterial isolates.

The detection limit of the method of $10^{4}$ copies per gram of background matrix is within the sensitivity range of endpoint PCR targeting individual genes (Leys et al., 2004). As such, although the method will suffer from drawbacks inherent to PCR like disclosing rare targets (Murray et al., 1996) and more efficient amplification of smaller regions compared to larger ones (Williams et al., 2006), it combines the ability to selectively recover long DNA fragments from eDNA with the high sensitivity of classic PCR. Moreover, agarose gel electrophoresis of the amplicons provides a first snapshot of the recovered amplicon sizes and hence provides a tool to rapidly examine differences in diversity between replicate samples and environments and to select samples for further NGS. Overall, the method extends the metagenomic mobilome toolbox that includes other molecular approaches like direct plasmid extraction combined with NGS or replicon typing by PCR-NGS (Sentchilo et al., 2013; Dealtry et al., 2014b).

\section{A large fraction of the gene functions on the $L R-P C R$ recovered IS1071 associated accessory regions encode for catabolic enzymes}

Sequence analysis of the contigs showed that the IS1071 composite transposons accessory genes recovered from the pesticide-treated environments often have a catabolic nature. KEGG analysis identified mainly lower 
pathway catabolic gene functions while HMMR and BLASTp led to the discovery of putative upstream catalytic functions in xenobiotic catabolic pathways (i.e. atzA and $h y(A)$. This observed discrepancy between analysis methodologies could primarily be attributed to the absence of plasmid-encoded genes in the BlastKOALA database (K. Morishima, 2016, pers. comm.). Both central and peripheral catabolic pathways included functions that could be directly linked to known pesticide biodegradation functions like hylA, dca-genes (Bers et al., 2013a), atzA (de Souza et al., 1998) and tfdA (Fukumori and Hausinger, 1993). hylA/dca are genes involved in the biodegradation of linuron, atz $A$ in the biodegradation of atrazine, and $t f d A$ in the biodegradation of cholorinated phenoxyacetic acids like 2,4-dichlorophenoxyacetic acid (2,4-D) and 2-methyl-4-chlorophenoxyacetic acid (MCPA). Degradation of atrazine and mineralization of linuron was shown in the BPS samples while mineralization of linuron was previously shown in the L SM A sample (Bers et al., 2013b), hence linking observed genotype with a community phenotype. The detection of the hylA/ dca-genes corroborates previous observations in both $\mathrm{L}$ SM A and another BPS environment, either using targeted PCR, exogenous plasmid isolation or cultivationdependent techniques (Horemans et al., 2016; Bers et al., 2013a; Dealtry et al., 2016; Martini et al., 2016). Interestingly, all three genotypes could also be linked to occurrence of the respective pesticide substrates the samples were exposed to, i.e. linuron in case of $L S M A$, and linuron and MCPA/2,4-D in case of BPS Kortrijk. Atrazine has been banned for use since many years but atzA can be linked to terbuthylzamine, another triazine compound with structure highly similar to atrazine, present in the wastewater (Caracciolo et al., 2010). Several other catabolic gene functions were recovered, including amidohydrolases and dioxygenases, which are likely involved in, but could not be directly linked to the degradation of a particular xenobiotic substrates. In BPS Kortrijk, besides triazine compounds, chlorinated phenoxyacetic acids and linuron, at least 33 other pesticides representing a wide range of chemical structures, were applied (Supporting Information Table S4) (Dunon et al., 2013; Dealtry et al., 2014b). The recovered catabolic accessory genes might thus play a role in the degradation of these compounds, for which the degradation pathways are often not known. Interestingly, two enzymes catalysing the conversion of nitriles (on contigs 5 and 44) were identified while the pesticides applied in the BPS included compounds containing nitrile groups like chlorotalonil and $\lambda$-cyhalothrin. In case of L SM A, the enrichment of unknown catabolic genes was clearly due to the application of linuron since no LR-PCR amplicons were recovered when no linuron was applied or after linuron application had been ceased for a longer period. The absence of LR-PCR amplicons and hence reduced abundance of IS1071 composite transposons below the detection limit in the latter control samples is in accordance with the findings of Bers et al. (2013b) and Horemans et al. (2016), observing both significant drops (factor 100-1000 till close to the PCR detection limit) in the abundance of the linuron hydrolytic gene functions $\operatorname{lib} A$ and hylA concomitant with a drop in the linuron mineralization efficiency. It remains unclear whether these 'unknown' degradative genes in the L SM A environment also contribute to the degradation of linuron by representing alternative catabolic routes, or whether they are merely gene clusters hitchhiking with linuron degrading bacteria that contained, for instance, hylA (Horemans et al., 2016).

The high incidence of catabolic genes mirrors the selective pressure in the studied environments

The impressively high incidence of (relevant) catabolic genes in association with IS1071 in both pesticidetreated environments shows that catabolic genes combined with IS1071 are highly enriched in such habitats. Moreover, their presence mirrors the major pollution these environments experienced, i.e. the application of organic xenobiotics, and hence mirrors the environmental selection. This is further accentuated by (i) the much higher diversity of IS1071 associated catabolic gene functions found in BPS Kortrijk compared to L SM A, consistent with exposure to a higher variety of pesticides in BPS Kortrijk compared to $L$ SM A receiving only linuron, (ii) the higher incidence of IS1071 associated catabolic genes in the pesticide-exposed environments compared to the controls and (iii) as illustrated above the direct link between several of the recovered catabolic functions and the pesticides to which the environments were exposed to. Our data thus strongly suggest that the catabolic IS1071 composite transposons were under strong selection from the organic pollutants, allowing their bacterial hosts to use these compounds as a carbon source or at least detoxify them. Currently, it is not clear whether this community adaptation involves simply enrichment of strains carrying the IS1071 associated genes, HGT or novel pathway construction on site. The LR-PCR approach allowed to have a cultivation-independent glance at the genetic context of catabolic genes in the microbial communities. The gene regions of the contigs that include hylA, dca and atzA showed remarkable nt identity and synteny with previously reported isofunctional gene regions bordered by IS1071 elements in bacterial strains (Bers et al., 2011, 2013a; Martinez et al., 2001) suggesting that the genetic context of these genes is quite conserved in the environment and apparently linked to IS1071. Therefore, their increased presence 
might be primarily linked with the growth of the original hosts or new hosts after gene transfer. On the other hand, several contigs showed partial but remarkable synteny with gene clusters in other organisms, which often did not contain nearby IS1071. This might indicate that they do not necessarily move together with IS1071 and hence were only recently integrated into an IS1071 carrying constellation. The integration might have been promoted by other IS elements that were often detected in the contigs. Many of the known IS1071 composite transposons have large accessory regions that also harbour other transposases. IS elements often associated with IS1071 are IS21 and IS66 (Król et al., 2012). IS21 was predominantly present in the recovered contigs and IS66 was also frequently detected. Interestingly, IS21 was often reoccurring in the sequences from the NCBI nt database that show significant synteny with gene clusters retrieved from the LR-PCR amplicons (Supporting Information Table S3). Furthermore, most of the organisms showing synteny were $\beta$-proteobacteria, which appear to be the preferential taxon for transposition of IS1071 among the proteobacteria (Sota et al., 2006). Whether or not the catabolic genes were conserved into an IS1071 constellation or were recently captured, their association with IS1071 make them prone to HGT and hence makes them a common benefit to the local microbial community. Indeed, even when originally present on a nontransferable replicon, the composite transposon might transpose onto more promiscuous replicons like conjugative plasmids (Fulthorpe and Wyndham, 1992). The promiscuous IncP-1 plasmids that were also enriched in BPS and linuron-treated agricultural soils (Dunon et al., 2013) make such an interesting vehicle for HGT of those IS1071 composite transposons, as was recently shown by the identification of $h y / A$ containing IncP-1 plasmids in the same BPS environment examined in the current study (Dealtry et al., 2016).

\section{The recovered IS1071 accessory regions contain a variety of non-catabolic gene functions and unknown genes}

Up to now, only two IS1071 based composite transposons were reported carrying gene functions that do not specify organic xenobiotic degradation, containing respectively an antibiotic resistance (Schlüter et al., 2003) and a metal resistance operon (accession number CP001644). Both can be considered as responsive to environmental selection. Interestingly, many genes were recovered with functions deviating from classical adaptive functions including genes that encode proteins that show similarity to proteins involved in membrane transport, ribosomal translation, signal transduction and cellular community, indicating that IS1071 can be involved in distributing other gene functions. These other gene functions are often present on contigs containing at least one putative catabolic gene function and hence they might be involved in optimizing the xenobiotic biodegradation function carried by the same transposon. Otherwise, they might improve the bacterial host's fitness in another yet unknown way. On the other hand, often the similarity for various non-catabolic proteins is below $40 \%$ when compared with a known protein sequence and therefore, it remains uncertain that these proteins perform the same function. An unexpected observation was the recovery of clusters of r-protein genes from agricultural soil sample $L$ SM A. Those genes seem to originate from Acidobacteria which are common soil bacteria (Kielak et al., 2016). The two corresponding contigs do not contain IS1071 remains at their sequence ends and therefore, at this stage, we cannot rule out that their presence would be due to unspecific amplification due to a high number of Acidobacteria in the L SM A soil sample. However, this is unlikely, since, besides the r-protein gene clusters, no other genes associated with Acidobacteria were recovered. The association of r-protein genes with IS1071 would make them prone to HGT. HGT gene transfer of informational genes like those encoding for r-proteins is considered unlikely. On the other hand, some phylogenetic studies show some unexpected tree topologies that (Makarova et al., 2001) suggest a role of HGT in the evolution of r-proteins.

In addition to genes encoding for non-catabolic proteins, a large fraction (30-40\%) of the genes in the recovered contigs could still not be assigned a known function, opening a window for an even broader range of enzyme functions to be associated with IS1071 elements. These results are reminiscent of a study by Sentchilo et al. (2013) that examined the plasmid metagenome from wastewater. These authors identified plasmid accessory genes involved in membrane transport and stress relief as well as a large number of unknown genes. As suggested by Sentchilo et al. (2013) for plasmids, our results suggest that IS1071 is a driving force for innovation of genetic information in bacteria (Sentchilo et al., 2013).

In conclusion, our LR-PCR approach extends observation from cultured isolates and shows that IS1071 is an omnipresent carrier of xenobiotic degradative functions in complex communities of pesticide impacted environments and might contribute to the environmental distribution and evolution of such genes as a response to pesticide pollution. The data can be further used as starting point to improve our understanding of the pesticide biodegradation functions in pesticide-contaminated ecosystems including the identification of new pathways and enzymes, of the environmental dynamics and abundance of IS1071 and its subtypes and of the mechanism of gene recruitment by IS1071 as well distribution of IS1071 
based composite transposons in microbial communities. Moreover, LR-PCR can be a powerful method to understand the ecological role of IS1071 in environmental settings in bacterial adaptation to environmental stressors different from organic pollution or sudden changes. It can also be used as a tool to mine interesting rare locally adaptive gene functions directly from the environment.

\section{Experimental procedures}

Plasmids used in this study

Plasmids carrying IS1071 composite transposons used in this study are presented in Table 1 and were propagated in various hosts. Corresponding cultivation media and conditions of the hosts are presented in Supporting Information.

\section{Chemicals used in this study}

Atrazine [2-chloro-4-ethylamine-6-isopropylamino-S-triazine] $(99.5 \%)$ was purchased from Sigma Aldrich (Belgium) and [phenyl-U-14C] linuron (627 MBq mmol-1, radiochemical purity $>95 \%$ ) from Izotop, Hungary.

\section{Environmental samples}

Environmental samples used in this study originated from an artificially composed BPS matrix (BPS pristine), from the matrix of a BPS in operation at a farm near Kortrijk, Belgium (BPS Kortrijk), and from a previously reported agricultural soil microcosm (SM) experiment. The nonpesticide treated artificial BPS matrix samples were composed of materials that are used in BPS and consisted of 25 vol\% straw, 25 vol\% coco chips and 50 vol\% flower soil. The BPS Kortrijk operational conditions and details about the BPS Kortrijk sampling procedure were described before (Dealtry et al., 2014b). Briefly, the BPS (length: $20 \mathrm{~m}$, width: $1.2 \mathrm{~m}$ ) was divided into four equal sampling sections. For each section, 12 cores $(\varnothing 4 \mathrm{~cm}$; $10 \mathrm{~cm}$ depth) were collected randomly, mixed and sieved. Samples were collected before start-up in March 2011, during the spraying season in July and September of the agricultural season of 2011 and just after the seasonal operational shut down of the BPS in December 2011. Supporting Information Table S4 provides a list of the active substances present in the wastewater during the agricultural season 2011. Actual pesticide concentrations though are unknown and variable over time. The agricultural soil SM experiment was described before by Bers et al. (2013b) and aimed at assessing the response of Variovorax and its linuron hydrolysis gene libA to linuron application in agricultural soil. Details about its setup and operation can be found in Bers et al. (2013b).
Briefly, SMs were glass columns filled with soil originating from an agricultural field with a history of linuron treatment. The SM experiment included two different treatments in triplicate: (i) irrigation with sterile tap water (triplicate microcosms 'W SM D', 'W SM E' and 'W SM $\left.F^{\prime}\right)$ and (ii) irrigation with sterile tap water containing $60 \mathrm{mg} \mathrm{I}^{-1}$ linuron (triplicate microcosms 'L SM A', 'L SM $B$ ' and ' $L S M C^{\prime}$ '). During the experiment, the treatment conditions changed for some replicate microcosms. Most importantly for this study, between days 285 and 491, the supply of linuron in microcosm 'L SM B' was replaced by adding tap water without linuron in order to confirm observed previously observed responses to linuron application/non-application. At days $0,28,110,149,245$ and 491, the soil was sampled from the microcosms for analysis. In this study, only the samples taken at day 491 were used for LR-PCR analysis.

\section{Plasmid DNA extraction}

Large plasmid DNA from bacterial cultures was isolated using an adapted alkaline lysis method (Sambrook and Russell, 2001) as reported in Supporting Information.

\section{eDNA extraction}

eDNA from the BPS Kortrijk samples for qPCR purposes was extracted using the FastDNA SPIN kit for Soil (MP Biomedicals) and further purified with the GENECLEAN Spin kit (Dealtry et al., 2014b). For all samples, high molecular weight eDNA for LR-PCR purposes was extracted from $300 \mathrm{mg}$ wet weight material using the MetaG-Nome ${ }^{\mathrm{TM}}$ DNA isolation kit from Epicentre with a slightly adapted protocol as reported in Supporting Information.

\section{Real-time PCR}

Quantification of IS1071 tnpA was performed by real-time PCR as described (Dunon et al., 2013). Significant differences in relative abundances between samples were examined by one-way analysis of variance (ANOVA; $p<0.05$ ) and post hoc Tukey test using SPSS (IBM, Armonk, NY).

\section{Long range $P C R$}

A database of 91 complete and incomplete IS1071 sequences (>1.5 kb; Accession numbers are in Supporting Information) was obtained by specific BLASTn searches and manually curated. Sequences were aligned with CLUSTAL X (Larkin et al., 2007) and a phylogenetic maximum likelihood tree was generated using MEGA6 (Tamura et al., 2013). Degenerate primers, IS1071_LR_1 (5'-ACAGGGTGGCCACCTCCAASGCCYGAAAC-3') and 
IS1071_LR_2 (5'-GAGCTGCTGATGGTCTAYGCCGGCATCAT-3'), were designed directing outwards in a highly conserved region of the tnpA gene. The IS1071 LR-PCR was performed in a volume of $25 \mu$ containing $1 \mathrm{U}$ Long PCR enzyme mix (Thermo Scientific, Germany) and $1 \times$ Long PCR buffer, $200 \mu \mathrm{M}$ of each dNTP, $0.1 \mathrm{mg} \mathrm{ml}^{-1} \mathrm{BSA}, 4 \%(\mathrm{v} / \mathrm{v}) \mathrm{DMSO}$ and $0.4 \mu \mathrm{M}$ and the primers IS1071_LR_1 and IS1071_LR_2. The LR-PCR included an initial denaturation of $2 \mathrm{~min}$ at $94{ }^{\circ} \mathrm{C}$, 10 cycles of $20 \mathrm{~s}$ at $94{ }^{\circ} \mathrm{C}$ and elongation of $16 \mathrm{~min}$ at $68^{\circ} \mathrm{C}$, followed by 25 cycles in which the elongation time was increased every cycle with $5 \mathrm{~s}$ and ended with an elongation step of $10 \mathrm{~min}$ at $68^{\circ} \mathrm{C}$. PCR products were separated by agarose gel electrophoresis $(0.8 \%)$ in Trisacetate/EDTA buffer and visualized using $1 \times$ GelRed $^{\mathrm{TM}}$ (Biotium, Fremont, CA).

\section{Southern blot hybridization}

Southern blot hybridization of LR-PCR products using a $d c a Q$ gene fragment as a probe was performed as described in Supporting Information.

\section{Pesticide mineralization and degradation assays}

${ }^{14} \mathrm{C}$-linuron mineralization assays were performed on $200 \mathrm{mg}$ (wet weight) of the environmental sample in MMO medium (Dejonghe et al., 2002) in triplicate and cumulative linuron mineralization curves composed as described (Sniegowski et al., 2011a, 2011b). Atrazine degradation assays were performed in triplicate in $75 \mathrm{ml}$ Erlenmeyer flasks containing $1 \mathrm{~g}$ (wet weight) of BPS material suspended in $25 \mathrm{ml}$ MMO that contained $15 \mathrm{mg} \mathrm{I}^{-1}$ atrazine. Abiotic controls containing sterilized BPS material (three times autoclaved), were included. The flasks were incubated on a horizontal shaker (125 rpm) at $20{ }^{\circ} \mathrm{C}$ in the dark for 13 days and $700 \mu \mathrm{l}$ samples taken regularly, acidified with $1 \mathrm{vol} \% \mathrm{HCl}(5 \mathrm{M})$ and centrifuged at $14000 \times g$ for $10 \mathrm{~min}$. Atrazine concentrations were quantified in the supernatant as reported previously (Cheyns et al., 2012).

\section{Sequencing and annotation}

LR-PCR amplicons were ethanol precipitated in $10 \mathrm{mM}$ Tris-HCl/EDTA [pH 8.0] and used for NGS by BGI Hong Kong. Paired-end sequencing $(2 \times 100 \mathrm{bp})$ was performed with the HiSeq 2000 (Illumina) platform. Two different runs were conducted using an insert library size of $200 \mathrm{bp}$ for the amplicons of BPS Kortrijk and L SM A and 500 bp for the amplicons of BPS pristine. Velvet 10.1 and Meta-Velvet (Zerbino and Birney, 2008) was used for reads assembly (see Supporting Information) and Bowtie 2 (version 2.2.5) for mapping back the reads on the contigs. Gene prediction and annotation was performed by RAST (Aziz et al., 2008), HMMER (Jeffryes et al., 2016), BLASTp (Ramsay et al., 2000) and Mega-BLAST (Altschul et al., 1997). KEGG Orthologies (KOs) were assigned by BlastKOALA (KEGG Orthology and Links Annotation) using the species_prokaryotes KEGG GENES database. Classification in functional categories was performed using the reconstruct pathway output (Kanehisa et al., 2016).

\section{Accession numbers}

Raw sequences are deposited in the Sequence Read Archive under the BioProjects: PRJNA278476 (BPS Kortrijk), PRJNA279102 (BPS Pristine) and PRJNA273666 ( $L$ SM A). Assembled and annotated contigs are deposited in the GenBank database with following accession numbers: KY206930-KY207245 (BPS Kortrijk), KY207246-KY207262 (BPS Pristine) and KY207263-KY207335 (L SM A).

\section{Acknowledgements}

This research was supported by IWT-Vlaanderen Strategic Basic Research project 91370, Fonds Wetenschappelijk Onderzoek (FWO) (G.0371.06) and the EU project METAEXPLORE (EU Grant No. 222625). The authors thank I. Veltens (KHLeuven) for her technical assistance and E. Krögerrecklenfort (JKI Braunschweig) and D. Sen (University of Idaho) for providing IncP-1 plasmids.

\section{References}

Altschul, S. F., Madden, T. L., Schäffer, A. A., Zhang, J., Zhang, Z., Miller, W., and Lipman, D. J. (1997) Gapped BLAST and PSI-BLAST: a new generation of protein database search programs. Nucleic Acids Res 25: 3389-3402.

Aziz, R. K., Bartels, D., Best, A., DeJongh, M., Disz, T., Edwards, R. A., et al. (2008) The RAST server: rapid annotations using subsystems technology. BMC Genomics 9: 75.

Bers, K., Batisson, I., Proost, P., Wattiez, R., De Mot, R., and Springael, D. (2013a) HylA, an alternative hydrolase for initiation of catabolism of the phenylurea herbicide linuron in Variovorax sp. strains. Appl Environ Microbiol 79: 5258-5263.

Bers, K., Leroy, B., Breugelmans, P., Albers, P., Lavigne, R., Sørensen, S. R., et al. (2011) A novel hydrolase identified by genomic-proteomic analysis of phenylurea herbicide mineralization by Variovorax sp. strain SRS16. Appl Environ Microbiol 77: 8754-8764.

Bers, K., De Mot, R., and Springael, D. (2013b) In situ response of the linuron degradation potential to linuron application in an agricultural field. FEMS Microbiol Ecol 85: 403-416.

Boon, N., Goris, J., De Vos, P., Verstraete, W., and Top, E. M. (2001) Genetic diversity among 3-chloroaniline- and aniline-degrading strains of the Comamonadaceae. Appl Environ Microbiol 67: 1107-1115.

Caracciolo, A. B., Fajardo, C., Grenni, P., Saccà, M. L., Amalfitano, S., Ciccoli, R., et al. (2010) The role of a 
groundwater bacterial community in the degradation of the herbicide terbuthylazine. FEMS Microbiol Ecol 71: 127-136.

Cheyns, K., Calcoen, J., Martin-Laurent, F., Bru, D., Smolders, E., and Springael, D. (2012) Effects of dissolved organic matter (DOM) at environmentally relevant carbon concentrations on atrazine degradation by Chelatobacter heintzii SalB. Appl Microbiol Biotechnol 95: 1333-1341.

Dealtry, S., Ding, G. C., Weichelt, V., Dunon, V., Schlüter, A., Martini, M. C., et al. (2014a) Cultivation-independent screening revealed hot spots of IncP-1, IncP-7 and IncP-9 plasmid occurrence in different environmental habitats. PLoS One 9: e89922.

Dealtry, S., Holmsgaard, P. N., Dunon, V., Jechalke, S., Ding, G.-C., Krögerrecklenfort, E., et al. (2014b) Shifts in abundance and diversity of mobile genetic elements after the introduction of diverse pesticides into an on-farm biopurification system over the course of a year. Appl Environ Microbiol 80: 4012-4020.

Dealtry, S., Nour, E. H., Holmsgaard, P. N., Ding, G.-C., Weichelt, V., Dunon, V., et al. (2016) Exploring the complex response to linuron of bacterial communities from biopurification systems by means of cultivation-independent methods. FEMS Microbiol Ecol 92: 1-12.

Dejonghe, W., Goris, J., Dierickx, A., Dobbeleer, V., Crul, K., De Vos, P., et al. (2002) Diversity of 3-chloroaniline and 3,4-dichloroaniline degrading bacteria isolated from three different soils and involvement of their plasmids in chloroaniline degradation. FEMS Microbiol Ecol 42: 315-325.

Dennis, J. J. (2005) The evolution of IncP catabolic plasmids. Curr Opin Biotechnol 16: 291-298.

de Souza, M. L., Seffernick, J., Martinez, B., Sadowsky, M. J., and Wackett, L. P. (1998) The atrazine catabolism genes atzABC are widespread and highly conserved. $J$ Bacteriol 180: 1951-1954.

Drolet, M., Zanga, P., and Lau, P. C. K. (1990) The mobilization and origin of transfer regions of a Thiobacillus ferrooxidans plasmid: relatedness to plasmids RSF1010 and pSC101. Mol Microbiol 4: 1381-1391.

Dunon, V., Sniegowski, K., Bers, K., Lavigne, R., Smalla, K., and Springael, D. (2013) High prevalence of IncP-1 plasmids and IS1071 insertion sequences in on-farm biopurification systems and other pesticide-polluted environments. FEMS Microbiol Ecol 86: 415-431.

Fang, H., Cai, L., Yang, Y., Ju, F., Li, X., Yu, Y., et al. (2014) Metagenomic analysis reveals potential biodegradation pathways of persistent pesticides in freshwater and marine sediments. Sci Total Environ 470-471: 983-992.

Fukumori, F., and Hausinger, R. P. (1993) Alcaligenes eutrophus JMP134 '2,4-dichlorophenoxyacetate monooxygenase' is an alpha-ketoglutarate-dependent dioxygenase. $J$ Bacteriol 175: 2083-2086.

Fulthorpe, R. R., and Wyndham, R. C. (1992) Involvement of a chlorobenzoate-catabolic transposon, Tn5271, in community adaptation to chlorobiphenyl, chloroaniline, and 2,4-dichlorophenoxyacetic acid in a freshwater ecosystem. Appl Environ Microbiol 58: 314-325.

Halak, S., Basta, T., Bürger, S., Contzen, M., Wray, V., Pieper, D. H., et al. (2007) 4-Sulfomuconolactone hydrolases from Hydrogenophaga intermedia S1 and Agrobacterium radiobacter S2. J Bacteriol 189: 6998-7006.
Horemans, B., Bers, K., Romero, E. R., Juan, E. P., Dunon, V., De Mot, R., et al. (2016) Functional redundancy of linuron degradation in microbial communities in agricultural soil and biopurification systems. Appl Environ Microbiol 82: 2843-2853.

Iwasaki, W., and Takagi, T. (2009) Rapid pathway evolution facilitated by horizontal gene transfers across prokaryotic lineages. PLoS Genet 5: e1000402.

Jeffryes, M., Liakata, M., and Bateman, A. (2016) Crowdsourcing protein family database curation. CEUR Workshop Proc 1747: W29-W37.

Kanehisa, M., Sato, Y., and Morishima, K. (2016) BlastKOALA and GhostKOALA: KEGG tools for functional characterization of genome and metagenome sequences. $J$ Mol Biol 428: 726-731.

Kielak, A. M., Barreto, C. C., Kowalchuk, G. A., van Veen, J. A., and Kuramae, E. E. (2016) The ecology of Acidobacteria: moving beyond genes and genomes. Front Microbiol 7: 744.

Kobayashi, M., and Shimizu, S. (1998) Metalloenzyme nitrile hydratase: structure, regulation, and application to biotechnology. Nat Biotechnol 16: 733-736.

Król, J. E., Penrod, J. T., McCaslin, H., Rogers, L. M., Yano, H., Stancik, A. D., et al. (2012) Role of IncP-1 $\beta$ plasmids pWDL7::rfp and pNB8c in chloroaniline catabolism as determined by genomic and functional analyses. Appl Environ Microbiol 78: 828-838.

Kumar, A., Trefault, N., and Olaniran, A. O. (2016) Microbial degradation of 2,4-dichlorophenoxyacetic acid: insight into the enzymes and catabolic genes involved, their regulation and biotechnological implications. Crit Rev Microbiol 42: 194-208.

Larkin, M. A., Blackshields, G., Brown, N. P., Chenna, R., McGettigan, P. A., McWilliam, H., et al. (2007) ClustalW and ClustalX version 2.0. Bioinformatics 23: 2947-2948.

Layton, A. C., Sanseverino, J., Wallace, W., Corcoran, C., and Sayler, G. S. (1992) Evidence for 4-chlorobenzoic acid dehalogenation mediated by plasmids related to pSS50. Appl Environ Microbiol 58: 399-402.

Lee, M. H., Mulrooney, S. B., Renner, M. J., Markowicz, Y., and Hausinger, R. P. (1992) Klebsiella aerogenes urease gene cluster: sequence of $u r e D$ and demonstration that four accessory genes (ure $D$, ure $E$, ure $F$, and ure $G$ ) are involved in nickel metallocenter biosynthesis. $J$ Bacteriol 174: 4324-4330.

Ledger, T., Pieper, D. H., and González, B. (2006) Chlorophenol hydroxylases encoded by plasmid pJP4 differentially contribute to chlorophenoxyacetic acid degradation. Appl Environ Microbiol 72: 2783-2792.

Leys, N. M. E. J., Ryngaert, A., Bastiaens, L., Verstraete, W., Top, E. M., and Springael, D. (2004) Occurrence and phylogenetic diversity of Sphingomonas strains in soils contaminated with polycyclic aromatic hydrocarbons. Appl Environ Microbiol 70: 1944-1955.

Ma, Y. F., Wu, J. F., Wang, S. Y., Jiang, C. Y., Zhang, Y., Qi, S. W., et al. (2007) Nucleotide sequence of plasmid pCNB1 from Comamonas strain CNB-1 reveals novel genetic organization and evolution for 4-chloronitrobenzene degradation. Appl Environ Microbiol 73: 4477-4483.

Makarova, K. S., Ponomarev, V. A., and Koonin, E. V. (2001) Two C or not two C: recurrent disruption of Zn-ribbons, gene duplication, lineage-specific gene loss, 
and horizontal gene transfer in evolution of bacterial ribosomal proteins. Genome Biol 2: RESEARCH 0033.

Martinez, B., Tomkins, J., Wackett, L. P., Wing, R., and Sadowsky, M. J. (2001) Complete nucleotide sequence and organization of the atrazine catabolic plasmid pADP-1 from Pseudomonas sp. strain ADP. J Bacteriol 183: 5684-5697.

Martini, M. C., Wibberg, D., Lozano, M., Torres Tejerizo, G., Albicoro, F. J., Jaenicke, S., et al. (2016) Genomics of high molecular weight plasmids isolated from an on-farm biopurification system. Sci Rep 6: 28284.

Müller, T. A., Fleischmann, T., van der Meer, J. R., and Kohler, H.-P. E. (2006) Purification and characterization of two enantioselective alpha-ketoglutarate-dependent dioxygenases, RdpA and SdpA, from Sphingomonas herbicidovorans MH. Appl Environ Microbiol 72: 4853-4861.

Murray, A. E., Hollibaugh, J. T., and Orrego, C. (1996) Phylogenetic compositions of bacterioplankton from two California estuaries compared by denaturing gradient gel electrophoresis of $16 \mathrm{~S}$ rDNA fragments. Appl Environ Microbiol 62: 2676-2680.

Nojiri, H., Shintani, M., and Omori, T. (2004) Divergence of mobile genetic elements involved in the distribution of xenobiotic-catabolic capacity. Appl Microbiol Biotechnol 64: 154-174.

Ramsay, L., Macaulay, M., Degli Ivanissevich, S., MacLean, K., Cardle, L., Fuller, J., et al. (2000) A simple sequence repeat-based linkage map of barley. Genetics 156: 1997-2005.

Sambrook, J., and Russell, D. W. (2001) Molecular Cloning: A Laboratory Mannual, 3rd ed. New York: Cold Spring Harbor Lab Press.

Schlüter, A., Heuer, H., Szczepanowski, R., Forney, L. J., Thomas, C. M., Pühler, A., et al. (2003) The 64508 bp IncP-1 $\beta$ antibiotic multiresistance plasmid pB10 isolated from a waste-water treatment plant provides evidence for recombination between members of different branches of the IncP-1 $\beta$ group. Microbiology 149: 3139-3153.

Sen, D., Yano, H., Suzuki, H., Król, J. E., Rogers, L., Brown, C. J., and Top, E. M. (2010) Comparative genomics of pAKD4, the prototype IncP-16 plasmid with a complete backbone. Plasmid 63: 98-107.

Sentchilo, V., Mayer, A. P., Guy, L., Miyazaki, R., Tringe, S. G., Barry, K., et al. (2013) Community-wide plasmid gene mobilization and selection. ISME J 7: 1173-1186.

Shin, K. A., and Spain, J. C. (2009) Pathway and evolutionary implications of diphenylamine biodegradation by Burkholderia sp. strain js667. Appl Environ Microbiol 75: 2694-2704.

Sniegowski, K., Bers, K., Van Goetem, K., Ryckeboer, J., Jaeken, P., Spanoghe, P., et al. (2011a) Improvement of pesticide mineralization in on-farm biopurification systems by bioaugmentation with pesticide-primed soil. FEMS Microbiol Ecol 76: 64-73.

Sniegowski, K., Bers, K., Ryckeboer, J., Jaeken, P., Spanoghe, P., and Springael, D. (2011b) Robust linuron degradation in on-farm biopurification systems exposed to sequential environmental changes. Appl Environ Microbiol 77: 6614-6621.

Sota, M., Kawasaki, H., and Tsuda, M. (2003) Structure of haloacetate-catabolic IncP-1 $\beta$ plasmid pUO1 and genetic mobility of its residing haloacetate-catabolic transposon. $J$ Bacteriol 185: 6741-6745.
Sota, M., Tsuda, M., Yano, H., Suzuki, H., Forney, L. J., and Top, E. M. (2007) Region-specific insertion of transposons in combination with selection for high plasmid transferability and stability accounts for the structural similarity of IncP-1 plasmids. J Bacteriol 189: 3091-3098.

Sota, M., Yano, H., Nagata, Y., Ohtsubo, Y., Genka, H., Anbutsu, H., et al. (2006) Functional analysis of unique class II insertion sequence IS1071. Appl Environ Microbiol 72: 291-297.

Sota, M., Yano, H., and Tsuda, M. (2008) Bacterial class II catabolic transposons. In DNA Transposable Elements Research, Yoshida, K., and Aoki, M. (eds). New York, NY: Nova Science Publishers, Inc, pp. 23-67.

Suenaga, H. (2012) Targeted metagenomics: a high-resolution metagenomics approach for specific gene clusters in complex microbial communities. Environ Microbiol 14: 13-22.

Tamura, K., Stecher, G., Peterson, D., Filipski, A., and Kumar, S. (2013) MEGA6: molecular evolutionary genetics analysis version 6.0. Mol Biol Evol 30: 2725-2729.

Tauch, A., Schlüter, A., Bischoff, N., Goesmann, A., Meyer, F., and Pühler, A. (2003) The 79,370-bp conjugative plasmid pB4 consists of an IncP-1 $\beta$ backbone loaded with a chromate resistance transposon, the strA-strB streptomycin resistance gene pair, the oxacillinase gene bla $a_{\text {NPS-1 }}$, and a tripartite antibiotic efflux system of the resistance-nodulation-division family. Mol Genet Genomics 268: 570-584.

Top, E. M., and Springael, D. (2003) The role of mobile genetic elements in bacterial adaptation to xenobiotic organic compounds. Curr Opin Biotechnol 14: 262-269.

Tsuda, M., Ohtsubo, Y., and Yano, H. (2014) Mobile catabolic genetic elements in Pseudomonads. In Biodegradative Bacteria: How Bacteria Degrade, Survive, Adapt, and Evolve, Nojiri, H., Tsuda, M., Fukuda, M., and Kamagata, Y. (eds). Tokyo, Japan: Springer, pp. 83-103.

van der Meer, J. R., Eggen, R. I. L., Zehnder, A. J. B., and de Vos, W. M. (1991) Sequence analysis of the Pseudomonas sp. strain P51 tcb gene cluster, which encodes metabolism of chlorinated catechols: evidence for specialization of catechol 1,2-dioxygenases for chlorinated substrates. J Bacteriol 173: 2425-2434.

Vedler, E., Vahter, M., and Heinaru, A. (2004) The completely sequenced plasmid pEST4011 contains a novel IncP1 backbone and a catabolic transposon harboring $t f d$ genes for 2,4-dichlorophenoxyacetic acid degradation. J Bacteriol 186: 7161-7174.

Williams R., Peisajovich S. G., Miller O. J., Magdassi S., Tawfik D. S., and Griffiths A. D. (2006) Amplification of complex gene libraries by emulsion PCR. Nat Methods 3: $545-550$.

Zerbino, D. R., and Birney, E. (2008) Velvet: algorithms for de novo short read assembly using de Bruijn graphs. Genome Res 18: 821-829.

\section{Supporting Information}

Additional Supporting Information may be found in the online version of this article at the publisher's web-site:

Appendix S1: Supplementary Material

Appendix S2: Supplementary Material

Appendix S3: Supplementary Material 